\title{
A review of sea-spray aerosol source functions using a large global set of sea salt aerosol concentration measurements
}

\author{
H. Grythe ${ }^{1,2,3}$, J. Ström ${ }^{1}$, R. Krejci ${ }^{1,4}$, P. Quinn ${ }^{5}$, and A. Stohl ${ }^{2}$ \\ ${ }^{1}$ Department of Applied Environmental Science (ITM), Atmospheric Science Unit, Stockholm University, 10691 Stockholm, \\ Sweden \\ ${ }^{2}$ Norwegian Institute for Air Research (NILU), P.O. Box 100, 2027 Kjeller, Norway \\ ${ }^{3}$ Finnish Meteorological Institute (FMI), Air Quality Research, Erik Palmenin aukio 1, P.O. Box 503, 00101 Helsinki, Finland \\ ${ }^{4}$ Division of Atmospheric Sciences, Department of Physics, University of Helsinki, P.O. Box 64 (Gustaf Hällströmin katu 2a) \\ 00014 University of Helsinki, Helsinki, Finland \\ ${ }^{5}$ NOAA Pacific Marine Environmental Laboratory, 7600 Sand Point Way NE, Seattle, 98115, WA, USA
}

Correspondence to: H. Grythe (zhg@ nilu.no)

Received: 16 July 2013 - Published in Atmos. Chem. Phys. Discuss.: 8 August 2013

Revised: 29 November 2013 - Accepted: 20 December 2013 - Published: 3 February 2014

\begin{abstract}
Sea-spray aerosols (SSA) are an important part of the climate system because of their effects on the global radiative budget - both directly as scatterers and absorbers of solar and terrestrial radiation, and indirectly as cloud condensation nuclei (CCN) influencing cloud formation, lifetime, and precipitation. In terms of their global mass, SSA have the largest uncertainty of all aerosols. In this study we review 21 SSA source functions from the literature, several of which are used in current climate models. In addition, we propose a new function. Even excluding outliers, the global annual SSA mass produced spans roughly 3-70 $\mathrm{Pg} \mathrm{yr}^{-1}$ for the different source functions, for particles with dry diameter $D_{\mathrm{p}}<10 \mu \mathrm{m}$, with relatively little interannual variability for a given function. The FLEXPART Lagrangian particle dispersion model was run in backward mode for a large global set of observed SSA concentrations, comprised of several station networks and ship cruise measurement campaigns. FLEXPART backward calculations produce gridded emission sensitivity fields, which can subsequently be multiplied with gridded SSA production fluxes in order to obtain modeled SSA concentrations. This allowed us to efficiently and simultaneously evaluate all 21 source functions against the measurements. Another advantage of this method is that sourceregion information on wind speed and sea surface temperatures (SSTs) could be stored and used for improving the SSA source function parameterizations. The best source functions reproduced as much as $70 \%$ of the observed SSA concentra-
\end{abstract}

tion variability at several stations, which is comparable with "state of the art" aerosol models. The main driver of SSA production is wind, and we found that the best fit to the observation data could be obtained when the SSA production is proportional to $U_{10}^{3.5}$, where $U_{10}$ is the source region averaged $10 \mathrm{~m}$ wind speed. A strong influence of SST on SSA production, with higher temperatures leading to higher production, could be detected as well, although the underlying physical mechanisms of the SST influence remains unclear. Our new source function with wind speed and temperature dependence gives a global SSA production for particles smaller than $D_{\mathrm{p}}<10 \mu \mathrm{m}$ of $9 \mathrm{Pg} \mathrm{yr}^{-1}$, and is the best fit to the observed concentrations.

\section{Introduction}

Ocean-derived aerosols are particles that are produced at the ocean surface and can remain suspended in the atmosphere for some time. Aerosols act as climate forcers both directly, by scattering and absorbing solar radiation, and indirectly, by affecting cloud microphysics as cloud condensation nuclei (CCN) (Köhler, 1925). Together with mineral dust, sea-spray aerosols (SSA) constitute the largest mass of particulate matter in the atmosphere, with an estimated global production rate of 3-30 $\mathrm{Pg} \mathrm{yr}^{-1}$ (Lewis and Schwartz, 2004). This makes SSA an important component of the climate system. The size 
of SSA particles ranges from smaller than $10 \mathrm{~nm}$ up to several millimeters. The SSA residence time in the atmosphere spans from seconds to days (Gong et al., 1997), depending on particle size and the effectiveness of removal mechanisms. Particles larger than about 5-10 $\mu \mathrm{m}$ in diameter typically have the shortest lifetimes, as they settle back to the surface with increasing effectiveness with size. Particles in the so-called accumulation-mode size range (around a few $100 \mathrm{~nm}$ ) are essentially only removed effectively by clouds and precipitation and therefore have the longest lifetime in the atmosphere. As the particle size decreases, the diffusivity increases, and the smallest particles are more prone to be removed by coagulation with other particles and dry deposition (de Leeuw et al., 2011).

The total anthropogenic direct effect of aerosols is estimated at $90 \%$ confidence to be from -0.1 to $-0.9 \mathrm{Wm}^{-2}$ and the indirect effect is estimated to be from -0.3 to $-1.8 \mathrm{Wm}^{-2}$ (IPCC, 2007). Combined, this makes the radiative effects of aerosols the largest uncertainty in climate modeling. This is related to a low level of scientific understanding. SSA contributes many times more to the global aerosol burden by mass than anthropogenic aerosol and it provides a substantial amount of CCN. Therefore proper quantification of SSA emission is an important task and better implementation of SSA in climate models is needed to improve our understanding of the role aerosols play in the climate system (Textor et al., 2006).

Most of the SSA is released in areas with otherwise low aerosol mass concentrations. This is important because the indirect aerosol effect in particular is not linear. Adding aerosol to a high pre-existing aerosol concentration has a smaller effect than adding the same amount of aerosol to a low pre-existing aerosol concentration (Twomey, 1977; Garrett et al., 2002). This makes the radiative budget and aerosol indirect effect especially sensitive to even small changes in aerosol loading in remote regions. Such changes can occur for SSA production due to changes in wind speed, sea surface temperatures, ice cover and salinity, all of which may be expected in a future changing climate. Knowledge of the amount of SSA emitted is also necessary to accurately calculate the anthropogenic aerosol effect.

The stress exerted by winds on the ocean surface causes waves to form and break. This force strongly and nonlinearly increases with increasing wind speed (Garrett, 1977). When waves break, the crest of the wave has its surface breached and air is entrained. The area where air bubbles are entrained is the so-called whitecap area, as the bubbles appear white. It is primarily these bubbles that are responsible for SSA production, as they rise in the water and can penetrate the ocean surface (Blanchard and Woodcock, 1957).

The production of SSA is due to three different mechanisms, and each of these mechanisms produces particles of different sizes (see Fig. 1). The smallest particles are from film droplets with a typical particle radius of less than $1 \mu \mathrm{m}$. They are produced from bubble bursting, which leaves bub- ble filaments above the water surface. Somewhat larger particles are produced by a jet filling in the void left at the ocean surface by the bubble. These jets produce aerosols with a typical radius of 1-10 $\mu \mathrm{m}$ (Blanchard, 1963). Larger particles still are produced as spume is torn off the wave crests, which only happens in strong winds (Monahan et al., 1986). Finally, splash drops are large drops with such short atmospheric lifetimes that they primarily may be considered in SSA production as a source of the other mechanisms when the drops resettle on the surface.

The effectiveness of the turbulent transport of SSA away from the ocean surface also affects SSA production. In the absence of turbulent vertical air motion, SSA would remain close to the surface and would have short lifetimes due to gravitational settling. Consequently the distinction between the effective production of SSA, i.e., the flux of particles through a surface at some height above the ocean and the flux at the surface becomes important for particles larger than dry diameter $D_{\mathrm{p}} \sim 3.5 \mu \mathrm{m}$ (Reid et al., 2001). The reference height is typically taken to be $10 \mathrm{~m}$.

While wind speed is certainly the most important factor in determining both the ocean surface production and the fraction of particles reaching the reference height, other aspects of the atmosphere and ocean may also be important. Indeed, as Hoppel et al. (1989) found by correlating wind speed and the number of SSA particles (ambient radius 1-9 $\mu \mathrm{m}$ ), local wind speed could explain only $16-64 \%$ of the variance in local SSA concentrations. Furthermore, with lifetimes of up to several days for the smaller particles their source region may be far away from the observation site, and thus SSA concentrations depend not only on the local conditions.

In this study the focus is on the source regions of a global set of observed marine aerosol concentrations. By use of a Lagrangian transport model it is possible to establish a source-receptor relationship between observed concentrations and upwind conditions, and thus source parameters can be investigated more closely. Another aim is to provide an overview of existing SSA flux parameterizations and to evaluate how well they can represent observed concentrations under different conditions. Finally, we recommend a SSA flux parameterization that best fits the large observational data set that we have collected.

\section{Sea salt aerosol production mechanisms}

The most common way to describe the amount of SSA released from an area of ocean is in terms of the net particle number flux through a plane reference surface above the ocean (Eq. 1). Most often this is given in terms of the number of aerosols by particle size by area by time (Lewis and Schwartz, 2004), the so-called source function. The reference surface of the source function is typically taken as a plane surface $10 \mathrm{~m}$ above the ocean surface, but it can also be at the ocean surface itself or at any other given altitude. The 


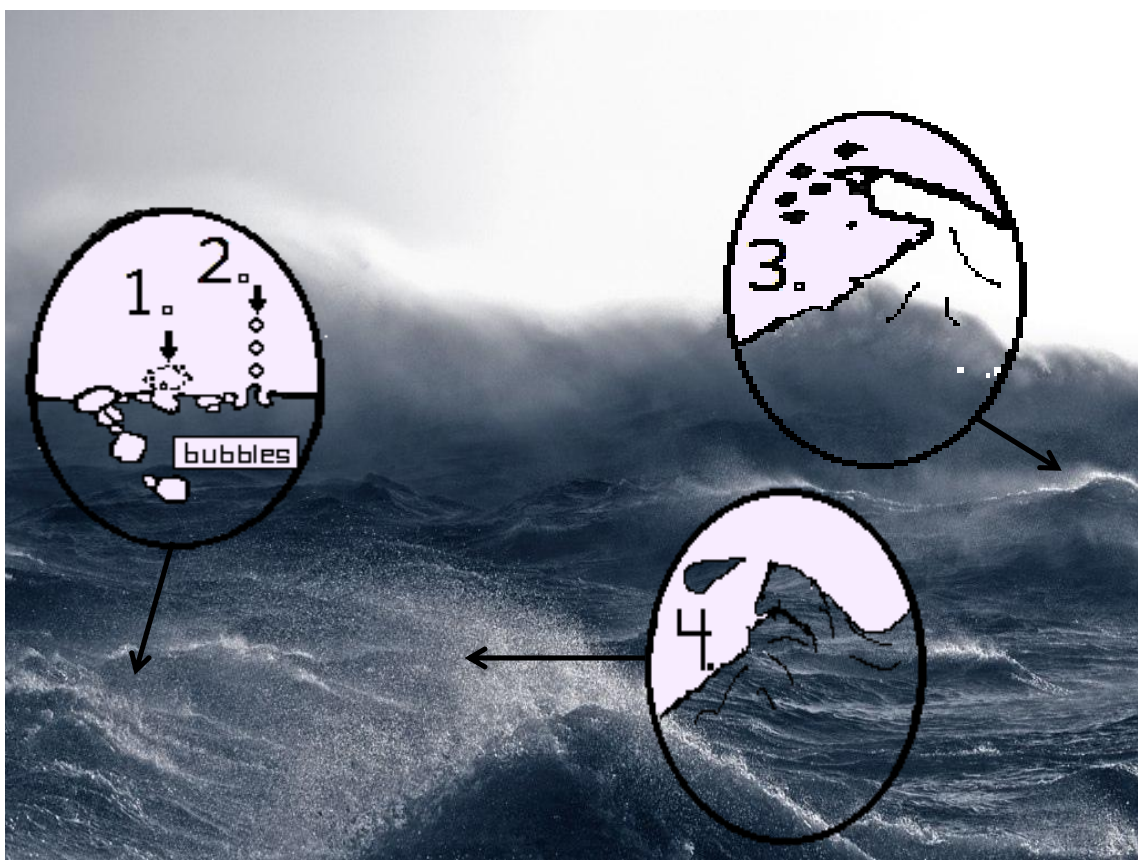

Fig. 1. Sea-spray aerosol generating mechanisms. 1. The smallest particles, typically with particle diameters less than $1 \mu \mathrm{m}$, are film droplets. They are produced from bubble bursting, and the filaments of the bubble are left above the water surface. 2. Somewhat larger particles are produced by the jet following the void left at the ocean surface by the bubble. These jet drops have a typical radius of 1-10 $\mu$ m. 3. Larger particles still are produced as spume is torn off the wave crests, which only happens in strong winds (Monahan et al., 1986). 4. The last depicted mechanism generates splash drops, which are large particles with such short lifetimes that they only participate in SSA production as a source of the other mechanisms.

general form of most source functions can be written as

$\frac{\mathrm{d} F\left(D_{\mathrm{p}}, U_{10}\right)}{\mathrm{d} D_{\mathrm{p}}}=W\left(U_{10}\right) \frac{\mathrm{d} F_{N} D_{\mathrm{p}}}{\mathrm{d} D_{\mathrm{p}}}$,

where $W\left(U_{10}\right)$ is the whitecap fraction of the ocean (see Fig. 2), or more generally, the magnitude of production. $W\left(U_{10}\right)$ is normally assumed to be dependent only on the $10 \mathrm{~m}$ wind speed, $U_{10}$ (de Leeuw et al., 2011). Previously proposed values for $W\left(U_{10}\right)$ are given in Appendix $\mathrm{A}$, and typically have a power law relationship with $W \propto U_{10}^{2}-U_{10}^{3.5}$. $F_{N}$ is the shape function which gives the relative number of SSA particles of an incremental dry diameter $D_{\mathrm{p}}$.

There is no clear convention on notation in reported SSA source functions; this has led to many ambiguities and makes direct comparisons between published source functions difficult. Therefore, an effort has been made in this study to harmonize the nomenclature and modify all source functions to a common reference. All source functions used in this study are reported in Appendix A.

For most practical purposes, the conversion between different SSA sizes can be approximated as (Andreas, 2002)

$2 r_{\mathrm{d}}=D_{\mathrm{p}} \simeq r_{80} \simeq \frac{1}{2} r_{0}$,

where $r_{\mathrm{d}}$ is the dry particle radius, $D_{\mathrm{p}}$ the dry particle diameter, $r_{80}$ the particle radius at $80 \%$ humidity (taken as a typical value in the maritime boundary layer) and $r_{0}$ is the mobilization radius, i.e., the radius at release. It then follows that fluxes can be converted using

$$
\frac{1}{2} \frac{\mathrm{d} F}{\mathrm{~d} r_{\mathrm{d}}}=\frac{\mathrm{d} F}{\mathrm{~d} D_{\mathrm{p}}} \simeq \frac{\mathrm{d} F}{\mathrm{~d} r_{80}} \simeq 2 \frac{\mathrm{d} F}{\mathrm{~d} r_{0}} .
$$

Several observable parameters may influence the effective production of SSA. Of these parameters, wind speed has the dominant influence and many studies have therefore only considered the dependence of SSA production on wind speed, while other studies have clearly shown the influence of other parameters as well. We will discuss the influence of each of these parameters and their treatment in source functions. The notation of a SSA source function in Eq. (1) can be generalized to account for other influences:

$$
\begin{aligned}
& \frac{\mathrm{d} F\left(D_{\mathrm{p}}, U_{10}, T, S, O\right)}{\mathrm{d} D_{\mathrm{p}}} \\
& =W\left(U_{10}, D_{\mathrm{p}}\right) \cdot \frac{\mathrm{d} F_{N} D_{\mathrm{p}}}{\mathrm{d} D_{\mathrm{p}}} \cdot T_{\mathrm{W}}\left(T, D_{\mathrm{p}}\right) \cdot S_{\mathrm{W}}\left(S, D_{\mathrm{p}}\right) \cdot O_{\mathrm{W}}\left(O, D_{\mathrm{p}}\right) .
\end{aligned}
$$

Here, $T$ and $S$ are the ocean temperature and salinity; $O$ is the sea state; and $T_{\mathrm{W}}, S_{\mathrm{W}}$ and $O_{\mathrm{W}}$ are the according weighting functions, i.e., the factor of offset in the production relative to a reference temperature/salinity/sea state. 

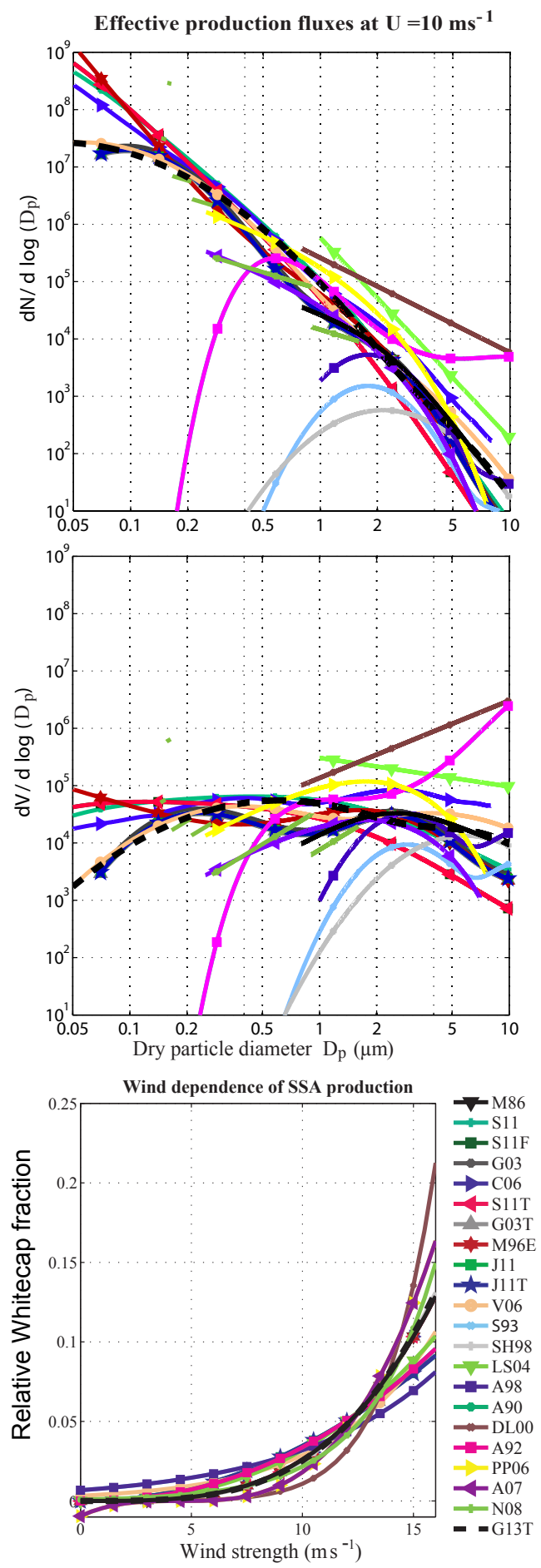

Fig. 2. Top: number density fluxes of several SSA-generating functions from the literature, for a wind speed of $15 \mathrm{~m} \mathrm{~s}^{-1}$. A total of 22 different functions are shown in this plot and they span several orders of magnitude for any given aerosol size; for details see Appendix. Middle: same as top, but for volume. Bottom: the windspeed dependence of SSA production for investigated source functions. For the source functions that have wind dependency varying with size, wind dependency is taken at $D_{\mathrm{p}}=1 \mu \mathrm{m}$. The graphs have been normalized to have the same area. For acronyms in the legend, see Table 1 .

\subsection{Wind}

Waves are generated due to the shear stress, $\tau$, exerted by the wind on the ocean surface. According to mixing length theory, the shear stress $\tau$ is given by (Prandtl, 1932)

$\tau=u_{*}^{2} \rho$,

where $\rho$ is the air density and $u_{*}$ the friction velocity in a stratified turbulent flow, which can be written as (Monin and Obukhov, 1954)

$u_{*}=\kappa \frac{u(z)}{\ln \left(z / z_{0}\right)}$,

where $u$ is the wind velocity at a height $z$ and $z_{0}$ is the roughness length. $\kappa$ is the von Karman constant, which for turbulent flows is approximately constant at $\kappa=0.35$ (Holton, 2004). Using parameterizations based on the friction velocity would then incorporate sea state parameters in the surface roughness $z_{0}$ which for the ocean surface depends on wave height and may be important for the amount of bubbles that are initiated (Geever et al., 2005). Although shear stress should ideally be used in parameterizations of whitecap cover and SSA production, most parameterizations are based on the more readily available $10 \mathrm{~m}$ winds and thus ignore variations in the state of the sea surface.

Shown in Fig. 3 is the European Centre for Medium-Range Weather Forecasting (ECMWF) ERA-40 (1985-2000) and operational reanalysis (2000-2012) of $10 \mathrm{~m}$ wind speeds over the oceans averaged over the time period 1985-2012 for June-August (JJA) and December-February (DJF). Strong winds with annual averages up to $\sim 10 \mathrm{~m} \mathrm{~s}^{-1}$ dominate in the westerlies in both hemispheres, while the tropics on average have weaker winds (the exception being the Horn of Africa). The seasonal variability, with a winter maximum and summer minimum, is stronger in the Northern Hemisphere $(\mathrm{NH})$ than in the Southern Hemisphere (SH). There is almost an order of magnitude difference in mean wind speeds for different areas of the globe (Fig. 3). Assuming the most commonly used dependence of whitecap fraction on wind speed, $U_{10}^{3.41}$ (Monahan and O'Muircheartaigh, 1980), the difference in whitecap fraction for e.g., 5 and $10 \mathrm{~ms}^{-1}$ winds translates into approximately a $1: 11$ difference in whitecap fraction. Differences even in time-averaged SSA production are, however, strongly amplified by temporal wind-speed variability, demonstrating that SSA production is highly variable both in space and in time.

\subsection{Temperature}

Temperature also has a significant influence on SSA production (e.g., Monahan et al., 1986; Mårtensson et al., 2003; Sellegri et al., 2006; Sofiev et al., 2011; Jaeglé et al., 2011; Zábori et al., 2012a). The water temperature influences the water surface tension, density and viscosity, all of which may all 

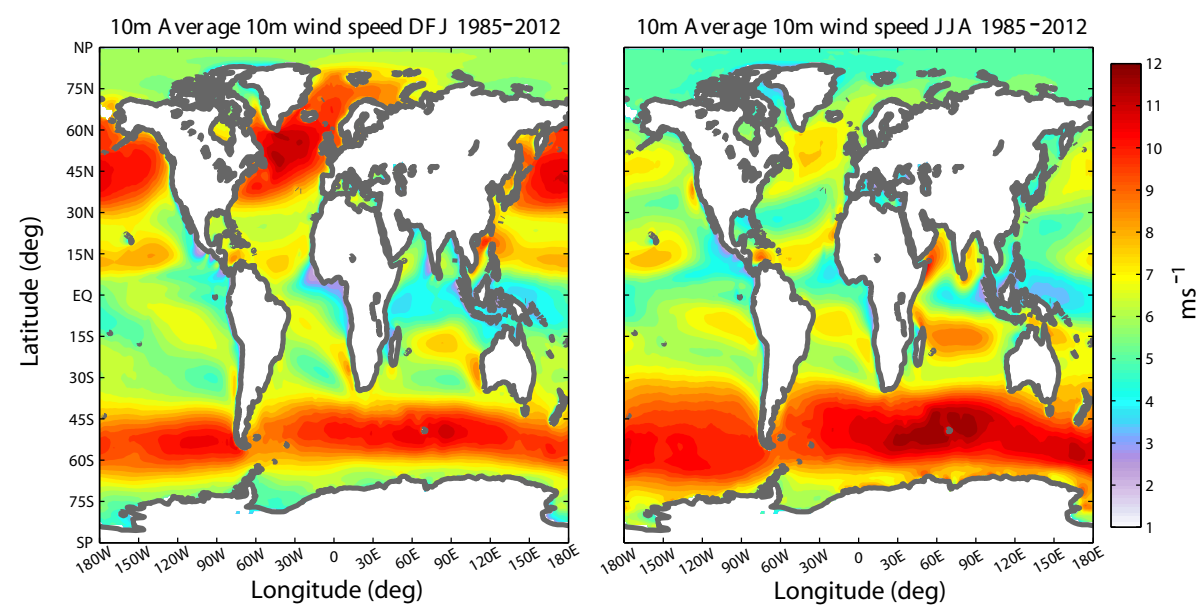

Fig. 3. December-February and June-August global $10 \mathrm{~m}$ wind speed over oceans obtained from ECMWF ERA-40 and operational analysis, averaged between 1985 and 2012.

affect SSA production both through bubble and wave breaking formation (e.g., Thorpe et al., 1992; Callaghan et al., 2012). For particles larger than about $D_{\mathrm{p}}=0.1 \mu \mathrm{m}$, Mårtensson et al. (2003) found a strong decrease in SSA production in cold water compared to that in warmer water, while for smaller particles the opposite was found. No physical explanation was offered by Mårtensson et al. (2003), but fewer bubbles in particular in the smaller size range (bubble radius $<30 \mu \mathrm{m}$ ) of the drops were produced in cold temperatures in their experiment.

The laboratory results of Mårtensson et al. (2003) were used by Sofiev et al. (2011) to develop interpolated temperature weights for temperatures ranging from -2 to $25^{\circ} \mathrm{C}$. In contradiction to this, Zábori et al. (2012a) found in laboratory experiments that for Arctic water, production of all sizes of SSA up to several tens of micrometers increases with decreasing temperatures in the temperature range -1 to $5^{\circ} \mathrm{C}$. A parameterization obtained by fitting model values to observed SSA concentrations showed a positive temperature dependence (Jaeglé et al., 2011); however, it was somewhat weaker than that of Mårtensson et al. (2003) fitted by Sofiev et al. (2011). The contradicting results of these studies underline the current lack of understanding about the role of temperature in SSA production.

\subsection{Ocean salinity}

A prerequisite for sea spray to produce SSA is that there is dissolved or particulate matter in the ocean. $90 \%$ of the salt dissolved in the oceans at about $33 \%$ is $\mathrm{NaCl}$. This constitutes most of the sea-spray-generated aerosol mass, together with smaller amounts of $\mathrm{SO}_{4}^{2-}, \mathrm{Mg}^{2+}, \mathrm{Ca}^{2+}$ and $\mathrm{K}^{+}$in other salts.

Some ocean physical properties that may influence the SSA production mechanism can be impacted by salinity. Firstly, the surface tension and density of the water are both affected by salinity, which in turn may influence the amount of whitecaps that are created as well as the bubble-bursting processes. Secondly, the mass of sea salt that a sea-spray droplet contains and thus can release depends directly on the salinity. Salinity is generally not considered an important factor in SSA production because it is relatively uniform across the world oceans. On a regional scale it can, however, be important. For instance, the salinity of the Mediterranean (up to $38 \%$ ) is some three times higher than that of the Baltic Sea (10-15\%). In a cold water tank experiment Zábori et al. (2012a) found increased amounts of SSA with salinity up to a salinity of $18 \%$; further increasing the salinity of artificial seawater had no observable effect (Zábori et al., 2012a). Based on this, most ocean water may be considered saturated with salts in regards to the amount of aerosols produced, since the ocean bodies' salinity seldom are lower than $30 \%$ o (Antonov et al., 2006).

\subsection{Wave properties}

Few studies have investigated how the sea state influences SSA production. Sea state parameters include wave direction, height, and shape. While closely linked to the wind, the sea state is not at equilibrium with the wind at any moment (Gemmrich et al., 2008). The fetch needed to build up waves increases with wind speed and may be several hundreds of kilometers for gale force or stronger winds. Ocean depth also influences wave properties as well as water currents. Especially when water depth gets smaller than the distance between wave crests, waves grow steeper and are more inclined to break and generate white water (Massel, 2007). There are many more subtle properties within wave field-wind interaction, such as changes in wind speed and direction (Callaghan et al., 2012), and old waves (swell) out-distancing/out-lasting the wind. One way to account for some of the ocean surface properties is to use the surface stress rather than the model 


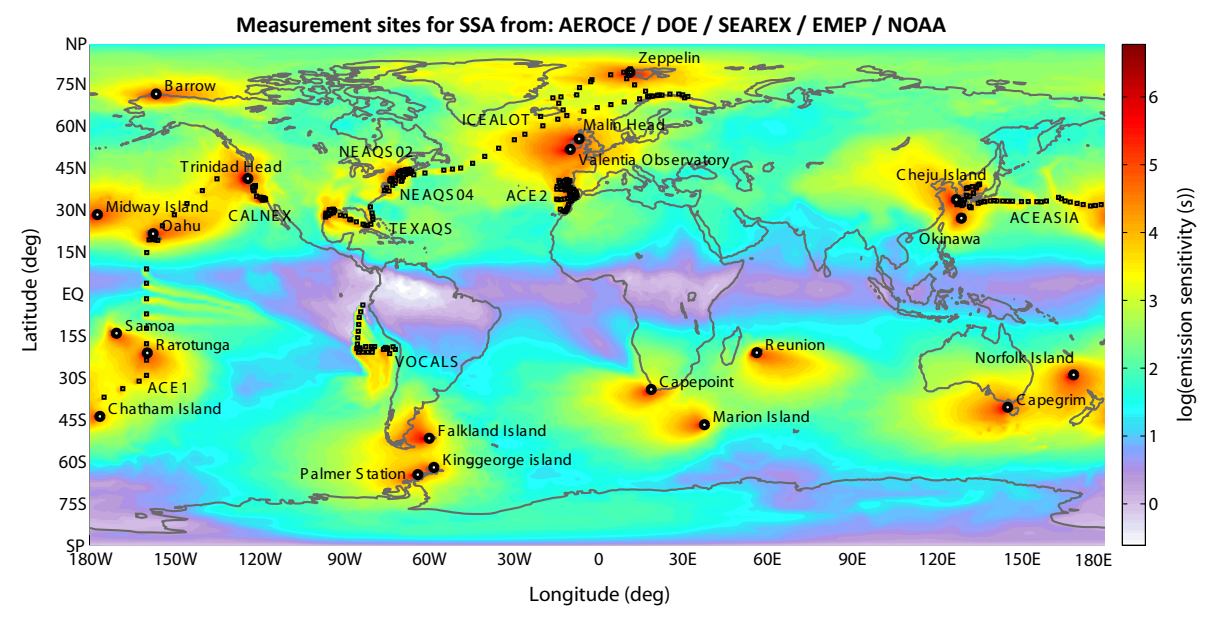

Fig. 4. Global map showing the locations of the stations (circles) and research cruises (dotted) (for station details, see Table 2). Also shown on a color scale is the combined footprint emission sensitivity of all the samples. This shows for which areas the observations provide information on the SSA emissions.

$10 \mathrm{~m}$ wind (Norris et al., 2008). However all the source functions considered in this study are based on $10 \mathrm{~m}$ wind rather than the surface stress.

\subsection{Organic surface active species}

The role of organic species in SSA production and characteristics is complex and not well understood. Organic matter can constitute a large portion of the ambient aerosol found in the marine atmosphere for particles with $D_{\mathrm{p}}<1 \mu \mathrm{m}$ (O'Dowd et al., 2004), although in terms of SSA, mass organic species are less important. The incorporation of organic substances has, however, been found to play an important role for the effective CCN size of SSA particles (O'Dowd et al., 2007).

Organic surface-active substances also influence the ocean surface's ability to form whitecaps (Callaghan et al., 2012). Laboratory experiments using artificial surfactants (sodium dodecyl sulphate and succinic acid) to represent microbiological activity have shown decreases in SSA production in water treated with these surfactants compared to untreated water (Sellegri et al., 2006; Zábori et al., 2012b). Organic compounds may also influence the lifetime of bubbles (Garrett, 1967). An increased bubble lifetime also leads to higher whitecap cover for the same number of bubbles produced. None of the considered source functions take this into account, and the fraction of organic mass is generally small when aerosol particles up to $D_{\mathrm{p}} 10 \mu \mathrm{m}$ is included.

\section{Observations}

Measurement data for our study were selected based on the availability of chemical analysis of $\mathrm{Na}^{+}$, which is sufficient to quantify the mass of sea salt in ambient aerosols in a marine environment (Prospero et al., 2005). Hence SSA can be approximated as $3.252 \times \mathrm{Na}^{+}$, reflecting the fraction of $\mathrm{Na}^{+}$ of the inorganic ions in sea water (Prospero et al., 2005).

Aerosols were collected for chemical analysis both during ship campaigns and at coastal observation sites. When selecting the measurement data sets used in our study, the aim was to get as good a global coverage as possible (see Fig. 4), in order to be able to evaluate SSA production for all conditions and climates. Table 1 lists all the observational sites and cruises that were included.

The SSA mass concentrations can be quantified by chemical analysis of aerosol filter samples. From the filters, the contents of inorganic anions $\left(\mathrm{Cl}^{-}, \mathrm{NO}_{3}^{-}, \mathrm{SO}_{4}^{2-}\right)$ and cations $\left(\mathrm{Ca}^{2+}, \mathrm{Mg}^{2+}, \mathrm{K}^{+}, \mathrm{Na}^{+}, \mathrm{NH}_{4}^{+}\right)$are measured most commonly by ion chromatography. Of these, in order of importance to the global average, SSA is $55 \% \mathrm{Cl}^{-}, 31 \% \mathrm{Na}^{+}, 8 \%$ $\mathrm{SO}_{4}^{2-}, 4 \% \mathrm{Mg}^{2+}, 1 \% \mathrm{Ca}^{2+}, 1 \% \mathrm{~K}^{+}$and $<1 \%$ other constituents (Frossard and Russell, 2012). The remaining SSA mass is of organic origin. Chemical analyses of the SSA compounds on the filter samples are quite similar for all the networks, but combining data from several observation networks implies that several different measurement techniques have been used in the data collection (see Table 1). Thus, not all values from different data sources may be directly comparable with each other; and therefore stations that use significantly different techniques from the bulk of data are left out of some comparisons.

We have used observational data obtained at 21 monitoring sites and on-board ships during 11 research cruises (Table 1). In total, the selected data sets consist of about 20000 observations, distributed to cover the world oceans as completely as possible. The measurements have been collected from a variety of data sources. Aerosols were reported as chemical analysis of either $\mathrm{PM}_{10}$ (all particulate matter smaller than $10 \mu \mathrm{m}$ ) or total suspended mass (TSM). The data were taken from 
Table 1. Overview of the observation data used in this study. The station/cruise locations are plotted in Fig. 4. TSM is total suspended particulate matter, and " 1 \& 10 " indicates $\mathrm{PM}_{10}$ concentrations.

\begin{tabular}{|c|c|c|c|c|c|c|}
\hline Station name & Network & Latitude & Longitude & Year & Sample duration & Type \\
\hline Zeppelin & EMEP & $79^{\circ} \mathrm{N}$ & $11^{\circ} \mathrm{E}$ & $2002-$ & $24 \mathrm{~h}$ & TSM \\
\hline Malin Head & EMEP & $55.2^{\circ} \mathrm{N}$ & $7^{\circ} \mathrm{W}$ & $2005-$ & $24 \mathrm{~h}$ & TSM \\
\hline Valentia Observatory & EMEP & $51.5^{\circ} \mathrm{N}$ & $10.1^{\circ} \mathrm{W}$ & $2005-$ & $24 \mathrm{~h}$ & TSM \\
\hline Barrow & NOAA/PMEL & $71.3^{\circ} \mathrm{N}$ & $156.6^{\circ} \mathrm{W}$ & 1997-2008 & 1 week & $1 \& 10$ \\
\hline Trinidad Head & NOAA/PMEL & $41.05^{\circ} \mathrm{N}$ & $124.15^{\circ} \mathrm{W}$ & 2002-2006 & 1 week & $1 \& 10$ \\
\hline ACE1 & NOAA/PMEL & $40^{\circ} \mathrm{N}-40^{\circ} \mathrm{S}$ & $170^{\circ} \mathrm{W}-120^{\circ} \mathrm{W}$ & 1995 & $<24 \mathrm{~h}$ & $1 \& 10$ \\
\hline ACE2 & NOAA/PMEL & $25^{\circ} \mathrm{N}-40^{\circ} \mathrm{N}$ & $10^{\circ} \mathrm{W}-0^{\circ} \mathrm{E}$ & 1997 & $<24 \mathrm{~h}$ & $1 \& 10$ \\
\hline ACEASIA & NOAA/PMEL & $35^{\circ} \mathrm{N}-40^{\circ} \mathrm{N}$ & $120^{\circ} \mathrm{E}-180^{\circ} \mathrm{E}$ & 2001 & $<24 \mathrm{~h}$ & $1 \& 10$ \\
\hline ICEALOT & NOAA/PMEL & $50^{\circ} \mathrm{N}-80^{\circ} \mathrm{N}$ & $60^{\circ} \mathrm{W}-60^{\circ} \mathrm{E}$ & 2008 & $<24 \mathrm{~h}$ & $1 \& 10$ \\
\hline NEAQS02 & NOAA/PMEL & $35^{\circ} \mathrm{N}-45^{\circ} \mathrm{N}$ & $75^{\circ} \mathrm{W}-65^{\circ} \mathrm{W}$ & 2002 & $<24 \mathrm{~h}$ & $1 \& 10$ \\
\hline NEAQS04 & NOAA/PMEL & $35^{\circ} \mathrm{N}-45^{\circ} \mathrm{N}$ & $75^{\circ} \mathrm{W}-65^{\circ} \mathrm{W}$ & 2004 & $<24 \mathrm{~h}$ & $1 \& 10$ \\
\hline TEXAQS & NOAA/PMEL & $20^{\circ} \mathrm{N}-35^{\circ} \mathrm{N}$ & $95^{\circ} \mathrm{W}-70^{\circ} \mathrm{W}$ & 2006 & $<24 \mathrm{~h}$ & $1 \& 10$ \\
\hline VOCALS & NOAA/PMEL & $20^{\circ} \mathrm{S}-0^{\circ} \mathrm{N}$ & $90^{\circ} \mathrm{W}-65^{\circ} \mathrm{W}$ & 2008 & $<24 \mathrm{~h}$ & $1 \& 10$ \\
\hline CALNEX & NOAA/PMEL & $30^{\circ} \mathrm{N}-40^{\circ} \mathrm{N}$ & $125^{\circ} \mathrm{W}-115^{\circ} \mathrm{W}$ & 2010 & $<24 \mathrm{~h}$ & $1 \& 10$ \\
\hline DYNAMO & NOAA/PMEL & $5^{\circ} \mathrm{N}-10^{\circ} \mathrm{N}$ & $80^{\circ} \mathrm{E}-95^{\circ} \mathrm{E}$ & 2011 & $<24 \mathrm{~h}$ & $1 \& 10$ \\
\hline Cape Grim & DOE & $40.68^{\circ} \mathrm{S}$ & $145^{\circ} \mathrm{E}$ & 1983-1996 & 1 week & TSM \\
\hline Cape Point & DOE & $34.35^{\circ} \mathrm{S}$ & $18.48^{\circ} \mathrm{E}$ & 1992-1996 & 1 week & TSM \\
\hline Chatham Island & DOE & $43.92^{\circ} \mathrm{S}$ & $176.5^{\circ} \mathrm{W}$ & 1983-1996 & 1 week & TSM \\
\hline Cheju Island (Jeju) & AEROCE & $33.52^{\circ} \mathrm{N}$ & $126.48^{\circ} \mathrm{E}$ & 1991-1995 & 1 week & TSM \\
\hline Falkland Island & DOE & $51.75^{\circ} \mathrm{S}$ & $60^{\circ} \mathrm{W}$ & 1987-1992 & 1 week & TSM \\
\hline King George island & DOE & $62.18^{\circ} \mathrm{S}$ & $58.3^{\circ} \mathrm{W}$ & 1990-1996 & 1 week & TSM \\
\hline Marion Island & DOE & $46.92^{\circ} \mathrm{S}$ & $37.35^{\circ} \mathrm{E}$ & 1992-1996 & 1 week & TSM \\
\hline Midway Island & SEAREX & $28.22^{\circ} \mathrm{N}$ & $177.35^{\circ} \mathrm{W}$ & $1981-2000$ & 1 week & TSM \\
\hline Norfolk Island & SEAREX & $29.08^{\circ} \mathrm{S}$ & $167.98^{\circ} \mathrm{E}$ & 1983-1997 & 1 week & TSM \\
\hline Oahu & SEAREX & $21.33^{\circ} \mathrm{N}$ & $157.7^{\circ} \mathrm{W}$ & 1981-1995 & 1 week & TSM \\
\hline Okinawa & SEAREX & $26.92^{\circ} \mathrm{N}$ & $128.25^{\circ} \mathrm{E}$ & 1991-1996 & 1 week & TSM \\
\hline Palmer Station & DOE & $64.77^{\circ} \mathrm{N}$ & $64.05^{\circ} \mathrm{W}$ & 1990-1996 & 1 week & TSM \\
\hline Rarotunga & SEAREX & $21.25^{\circ} \mathrm{S}$ & $159.75^{\circ} \mathrm{W}$ & 1983-1994 & 1 week & TSM \\
\hline Reunion & DOE & $21.17^{\circ} \mathrm{S}$ & $55.83^{\circ} \mathrm{E}$ & 1990-1996 & 1 week & TSM \\
\hline Samoa & SEAREX & $14.25^{\circ} \mathrm{S}$ & $170.58^{\circ} \mathrm{W}$ & 1983-1999 & 1 week & TSM \\
\hline
\end{tabular}

- NOAA's (US National Oceanic and Atmospheric Administration's) PMEL (Pacific Environmental Marine Laboratory) data,

- EMEP (European Monitoring and Evaluation Programme),

- EUSAAR (European Supersites for Atmospheric Aerosol Research),

- and GAW (Global Atmosphere Watch).

- Data dating back to the 1980s was taken from the AEROCE (Aerosol Oceanic Chemistry Experiment) (Arimoto, 1992),

SEAREX (Asian dust network in the North Pacific) (Saltzman et al., 1985),

and DOE (US Department of Energy collected and analyzed; (e.g., Prospero et al., 2003))

networks, all collected by Joseph M. Prospero.
With the exception of the NOAA stations, where aerosol particles were dried to between 5 and $55 \% \mathrm{RH}$, all aerosol particles were sampled at ambient RH. The most important difference between the samples, however, is that for the collection of some filter samples, open-faced filters were used (e.g., EMEP). Conversely, for the ship campaign data (i.e., NOAA data; see Table 1) multi stage impactors were used. Multi stage impactor samples provide information about submicron $(<1 \mu \mathrm{m})$ and supermicron $(1-10 \mu \mathrm{m})$ particles. Combining these two size ranges gives a sea salt mass of particles smaller than $10 \mu \mathrm{m}$, which is hereafter referred to as $\mathrm{PM}_{10}$. The actual impactor cut-off will be smaller than $D_{\mathrm{p}}=$ $10 \mu \mathrm{m}$ due to the high density of SSA and the added liquid water still attached to the aerosol particles at the sampled RH. This implies that the residual SSA is smaller than $D_{\mathrm{p}}=10 \mu \mathrm{m}$, and lies between $D_{\mathrm{p}}=6-8 \mu \mathrm{m}$ depending on the RH (Berner et al., 1979).

For the EMEP stations some comparisons have been made between the $\mathrm{PM}_{10}$ measurements and open-faced filters and 


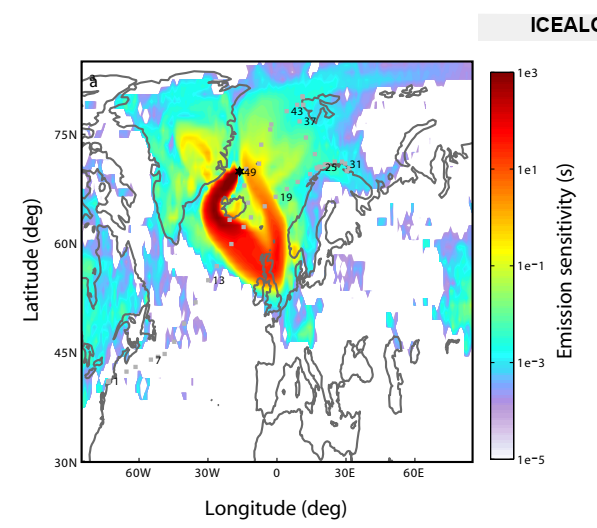

ICEALOT

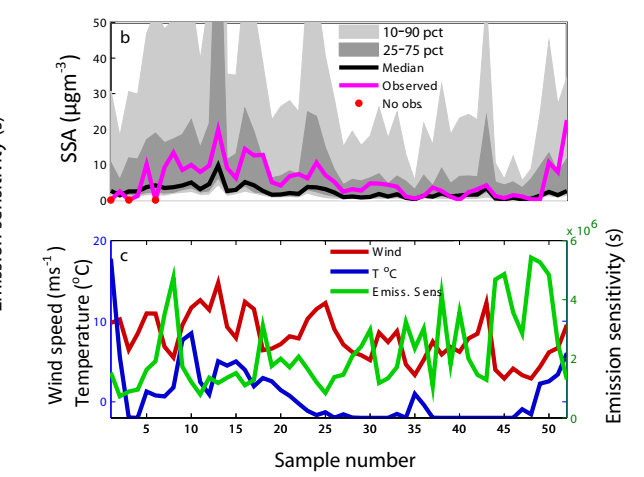

Fig. 5. (a) FLEXPART footprint emission sensitivity for the $10 \mathrm{~h}$ long 49th observation from ICEALOT, taken north of Iceland (black star) on 24 April 2008. The color scale indicates where, at any time during the past 20 days, the observation is sensitive to emission. (b) SSA concentration time series for the NOAA cruise ICEALOT. The solid pink line shows the observed PM $_{10}$ concentrations along the ship track, for samples taken over durations of 8 to $24 \mathrm{~h}$. The black line is the FLEXPART-simulated SSA concentration, averaged over 22 different source functions. The dark gray area shows the interquartile range (25-75\%) of all simulated concentrations, while the light gray area shows the 10-90\% range. (c) The mean temperature, wind speed and total footprint emission sensitivity over the ocean surface of the air mass before being sampled (marine footprint) for all the ICEALOT observations. The wind and temperature means are weighted by the footprint emission sensitivity.

under most conditions the differences were below $10 \%$ (W. Aas, personal communication, 2013). For these comparisons, it was not tested whether the small differences were due to an actual cut-off of the open-faced filter near $10 \mu \mathrm{m}$, or whether there simply was not much particulate mass with sizes larger than $10 \mu \mathrm{m}$. For the non-EMEP open-faced filters we are not aware of any comparison with $\mathrm{PM}_{10}$ measurements, but we acknowledge that the non-EMEP stations have a different setup from EMEP. It can thus be noted that, at least at some distance away from the source, differences in sodium content between $\mathrm{PM}_{10}$ and TSM measurements are small.

Theoretical cut-off for the open-faced filters can be calculated based on aerosol density and size, sampling flow rate and filter-face area. Based on the EMEP filter diameter $(47 \mathrm{~mm})$ and flow rate, the cut-off at $\mathrm{RH}=80 \%$ would be, for $\mathrm{NaCl}$ particles with $r_{80}, 11-14 \mu \mathrm{m}$. Additional factors such as wind speed may influence this theoretical value, and this makes the estimates more uncertain.

Three of the networks, SEAREX, DOE and AEROCE (and also the NOAA stations Trinidad Head and Barrow), sampled aerosols only when the wind was coming from a particular sector, and these stations may have had as little as a few percent of actual sampling time if the prevailing wind was from outside the sector. Therefore, the observed values may not be very representative of the average concentration during the total sampling period. Where information on sampling rate and sampled volume was available, observations that sampled less than $80 \%$ of the total sampling period were discarded. Several stations, at which sectored sampling was applied, had a narrow sampling sector - they rarely sampled more than a few tenths of a percent of the sampling time, were thus excluded from our study. For the EMEP stations, long time series were limited to two years of measurements. This was done to avoid having too many measurements at one place. Finally, all individual samples that were flagged or erroneous were left out of the further analysis. This left a total of 15341 observations from 32 stations and ship campaigns (Table 1) for which the model was run.

\section{Method}

\subsection{SSA source functions}

All the source functions, i.e., whitecap fraction or amplitude, shape functions, and weighting functions used to calculate SSA production in this study, are listed in Table 2 and are presented in detail in Appendix A. They were used in the form of Eq. (1) or, if temperature was included or wind dependence also depended on aerosol size, in the more general form of Eq. (4).

The large number of existing source functions reflects the fact that, so far, no single source function has been found that performs best under all conditions. The largest differences between these functions are due to differences in the shape function and the wind dependence. Most source functions are not based on a compilation of current knowledge, but are rather based on data from single experiments or measurement campaigns. While more than 50 different source functions were considered in total in our study, some that are very similar to earlier published ones and others that were incompletely described were excluded from further analysis. Finally, 21 source functions were selected for detailed evaluation against the measurement data, including the most widely used and the newly proposed source function. 
Table 2. List of all the source functions used in this paper. For sake of brevity, the acronym is used throughout the text. $D_{\mathrm{p}}$ gives the validity size range in $\mu \mathrm{m}$ dry diameter. "Type" is the method that the authors have used to produce the source function. "Mean" is the annual average global production averaged over the $25 \mathrm{yr}$ of ECMWF data available, and " \pm " is the difference in mass between maximum and minimum year, which is also given in Pg. "Bias" gives the relative bias in percent calculated for the modeled concentration compared to the mean of the combined $\mathrm{PM}_{10}$ and EMEP measurements. Pearson's correlation coefficient is reported for the entire data set $\left(r_{\mathrm{a}}\right)$, for the PM 10 observations only, $\left(r_{\mathrm{PM}_{10}}\right)$, for the EMEP data $\left(r_{e}\right)$, and for the week-long TSM measurements $\left(r_{\mathrm{W}}\right)$. For the data subsets, the mean station correlation is reported (and not, as for $r_{\mathrm{a}}$, the correlation for the set of data as a whole.

\begin{tabular}{|c|c|c|c|c|c|c|c|c|c|c|}
\hline Reference & Acronym & $D_{\mathrm{p}}$ & Type & $\mathrm{Pgyr}^{-1}$ & \pm & Bias & $r_{\mathrm{a}}$ & $r_{\mathrm{PM}_{10}}$ & $r_{e}$ & $r_{\mathrm{W}}$ \\
\hline Monahan et al. (1986) & M86 & $0.8-8$ & Exp. & 4.51 & 0.44 & -49 & 0.25 & 0.58 & 0.77 & 0.31 \\
\hline Sofiev et al. (2011) & S11 & $0.01-10$ & Modified & 5.87 & 0.57 & -37 & 0.25 & 0.58 & 0.78 & 0.32 \\
\hline Sofiev et al. (2011) & $\mathrm{S} 11 \mathrm{~F}$ & $0.01-10$ & Modified & 1.83 & 0.18 & -80 & 0.25 & 0.58 & 0.78 & 0.31 \\
\hline Gong (2003) & G03 & $0.07-20$ & Lab. & 5.95 & 0.58 & -35 & 0.25 & 0.58 & 0.78 & 0.31 \\
\hline Clarke et al. (2006) & C06 & $0.01-8$ & Surf exp. & 22.6 & 2.19 & 117 & 0.27 & 0.58 & 0.79 & 0.32 \\
\hline Sofiev et al. (2011) & $\mathrm{S} 11 \mathrm{~T}$ & $0.01-10$ & Modified & 2.59 & 0.33 & -79 & 0.41 & 0.58 & 0.75 & 0.30 \\
\hline Gong (2003) & G03T & $0.07-20$ & Modified & 4.59 & 0.57 & -65 & 0.25 & 0.58 & 0.79 & 0.32 \\
\hline Monahan et al. (1986) & M86E & $0.1-10$ & Exp. & 5.20 & 0.50 & -43 & 0.26 & 0.58 & 0.78 & 0.31 \\
\hline Jaegle et al. (2011) & $\mathrm{J} 11$ & $0.07-20$ & Model & 4.86 & 0.34 & -44 & 0.26 & 0.43 & 0.67 & 0.20 \\
\hline Jaegle et al. (2011) & $\mathrm{J} 11 \mathrm{~T}$ & $0.07-20$ & Model & 4.20 & 0.39 & -55 & 0.41 & 0.39 & 0.69 & 0.20 \\
\hline Vignati et al. (2006) & V06 & $<20$ & Model & 17.43 & 1.01 & 126 & 0.28 & 0.37 & 0.66 & 0.14 \\
\hline Smith et al. (1993) & S93 & $0.3-25$ & Exp. & 2.90 & 0.20 & -59 & 0.28 & 0.31 & 0.70 & 0.16 \\
\hline Smith and Harrison (1998) & SH98 & $1-300$ & Dry dep. & 6.67 & 0.66 & -33 & 0.28 & 0.59 & 0.80 & 0.34 \\
\hline Lewis and Swhartz (2004) & LS04 & $1-25$ & Multiple & 73.53 & 5.82 & 641 & 0.29 & 0.54 & 0.76 & 0.27 \\
\hline Andreas (1998) & A98 & $1-20$ & Modified & 10.14 & 0.69 & 31 & 0.25 & 0.48 & 0.64 & 0.35 \\
\hline Andreas (1990) & A90 & $0.08-15$ & Multiple & 605 & 43.8 & 991 & 0.33 & 0.51 & 0.78 & 0.28 \\
\hline de Leeuw et al. (2000) & DL00 & $0.8-10$ & Surf Exp. & 2444 & 491 & 8007 & 0.16 & 0.38 & 0.42 & 0.16 \\
\hline Andreas (1992) & A92 & $0.08-15$ & Modified & 5.65 & 0.45 & -46 & 0.29 & 0.58 & 0.73 & 0.34 \\
\hline Petelski and Piezkoub (2006) & PP06 & $0.25-7.5$ & Exp. & 167.8 & 0.92 & 895 & 0.29 & 0.51 & 0.77 & 0.27 \\
\hline Andreas (2007) & A07 & $0.25-7.5$ & Modified & 7.09 & 14.44 & -24 & 0.19 & 0.49 & 0.69 & 0.29 \\
\hline Norris et al. (2008) & N06 & $<2.4$ & Field. & 3.25 & 0.68 & -71 & 0.17 & 0.30 & 0.46 & 0.26 \\
\hline Grythe et al. (2013) & G13T & $0.01-10$ & Model & 8.91 & 0.61 & -18 & 0.41 & 0.60 & 0.81 & 0.34 \\
\hline
\end{tabular}

To calculate SSA emissions, operational analyses from the European Centre for Medium-Range Weather Forecasts (ECMWF) were combined with each individual source function. The $10 \mathrm{~m}$ wind speed and sea surface temperature (SST) were used as inputs to the different source functions in order to obtain the calculated SSA mass flux for each grid cell at $3 \mathrm{~h}$ time intervals. The availability of wind data for this long period made it necessary to combine two different data sets. For the period from January 2000, operational analyses, with analyses every $6 \mathrm{~h}$ (at 00:00, 06:00, 12:00 and 18:00 UTC) and three-hour intermediate forecasts were used. ECMWF fields with a $1^{\circ} \times 1^{\circ}$ horizontal resolution and with 91 vertical levels were used. For the period 1980-2000, ECMWF ERA-40 re-analysis (Uppala et al., 2005) data with the same horizontal and temporal resolution, but with 61 vertical levels, are used.

\subsubsection{A new sea-spray aerosol source function}

Based on the model source region, average temperature, and wind (Sect. 4.2), an empirical fit was made to the data and a new source function obtained. Several variations of existing functions were tested, both by changing the mass of all aerosol sizes and by changing the windspeed dependence. By using the global wind-speed distribution (Sect. 5.2), an approximate annual mass production from a number flux could be estimated for any given production wind-dependence. Applying the same method as for the other source functions (Sect. 4.2) the new source function was optimized to fit the observational data, primarily in regards to three aspects; wind- and temperature-dependence of production and total mass flux for each modal size in the model.

The best fit to the data was obtained by using a modified SH98 (see Appendix A for reference abbreviations) source function, hereafter referred to as G13T, which can be seen as a dashed black line in Fig. 2. The original SH98 parameterization did not cover particles smaller than $D_{\mathrm{p}}=1 \mu \mathrm{m}$. The modification was to add a lognormal particle distribution for the particles produced by the filament and jet producing mechanisms in Fig. 1 from $0.01-\sim 4 \mu \mathrm{m}$. The added lognormal mode of particles was given the amplitude to best fit the collected source functions that cover accumulation mode, and was centered at $0.1 \mu \mathrm{m}$. It was tested with all available temperature dependencies (no temperature dependence, Eq. (10), the temperature dependence of J11T (Eq. A7) and 
S11T (Eq. A4)). The temperature weight of J11T fits the data the best and is therefore recommended as $T_{\mathrm{W}}$.

The new source function, with three lognormal modes we suggest is:

$$
\begin{aligned}
& \frac{\mathrm{d} F\left(D_{\mathrm{p}}, U_{10}, T\right)}{\mathrm{d} D_{\mathrm{p}}}=T_{\mathrm{W}} \cdot\left[235 \cdot U_{10}^{3.5} \exp \left(-0.55\left[\ln \left(\frac{D_{\mathrm{p}}}{0.1}\right)\right]^{2}\right)\right. \\
& \left.+0.2 \cdot U_{10}^{3.5} \exp \left(-1.5\left[\ln \left(\frac{D_{\mathrm{p}}}{3}\right)\right]^{2}\right)+6.8 \cdot U_{10}^{3} \exp \left(-1\left[\ln \left(\frac{D_{\mathrm{p}}}{30}\right)\right]^{2}\right)\right] .
\end{aligned}
$$

The source function Eq. (7), G13T, was applied by the same method as the source functions in Appendix A in the model. The best fit for $T_{\mathrm{W}}$ was found to be Eq. (A7) which has an increase in production with $T_{\mathrm{W}}(T)=0.3+0.1 T-0.0076 T^{2}+$ $0.00021 T^{3}$. When modeled without accounting for temperature $\left(T_{\mathrm{W}}=1\right)$, it is referred to as G13.

\subsection{Model}

The model used to simulate SSA transport from the sources to the measurement stations is FLEXPART, a Lagrangian particle dispersion model (Stohl et al., 2005). It computes trajectories of particles in the atmosphere to describe the transport and turbulent diffusion of atmospheric tracers. It has previously been applied and validated within diverse fields of research, such as the study of global air pollution transport (Stohl et al., 2003; Eckhardt et al., 2003), the identification of forest fire plumes (e.g., Forester et al., 2001) and volcanic plumes (Stohl et al., 2011), and the study of long-range transport to the Arctic (Stohl, 2006). The same meteorological analyses from ECMWF used for calculating SSA production were also used to drive FLEXPART.

Particle trajectories in FLEXPART follow the mean flow of air plus random motions to account for turbulence. Turbulence is smaller in the free troposphere than in the boundary layer, and smaller still in the stratosphere. Dispersion in the boundary layer (BL) is calculated by assuming Gaussian turbulence and solving the stochastic Langevin equations (Stohl and Thomson, 1999). Dry deposition of particulate matter in FLEXPART is parameterized by

$v_{\mathrm{d}}=\left[r_{\mathrm{a}}(z)+r_{\mathrm{b}}+r_{\mathrm{a}}(z) r_{\mathrm{b}} v_{\mathrm{g}}\right]^{-1}+v_{\mathrm{g}}$

$v_{\mathrm{g}}=\frac{g \rho_{\mathrm{p}} D_{\mathrm{p}}^{2} C_{\mathrm{cunn}}}{18 \mu}$

where $v_{\mathrm{d}}$ is the dry deposition velocity and $v_{\mathrm{g}}$ is the gravitational settling velocity. $r_{\mathrm{a}}$ is the aerodynamic resistance and $r_{\mathrm{b}}$ the quasi-laminar sublayer resistance. $C_{\text {cunn }}$ and $\mu$ are Cunningham's slip flow correction and the dynamic viscosity of air, respectively. $\rho_{\mathrm{p}}$ and $r_{80}$ are the density and radius, respectively, at $80 \% \mathrm{RH}$ of the aerosol. Dry deposition is implemented in FLEXPART by reducing a particle's mass when it comes close to the surface. Furthermore, gravitational settling is superimposed on the trajectory of every particle (see Stohl et al., 2005, for details).
Wet deposition of particulate matter in FLEXPART is differentiated into two parts: in-cloud and below-cloud scavenging. In-cloud scavenging for particulate matter is parameterized using the scavenging coefficient $\left(s^{-1}\right) \Delta_{i}=\left(S_{i} I\right) / H_{i}$, where $S_{i}=0.9 / \mathrm{cl}$, and the cloud liquid water content, $\mathrm{cl}=$ $2 \cdot 10^{-6} I^{0.36}$, is parameterized as a function of precipitation intensity $I$. Below-cloud scavenging is represented by $\Delta_{\mathrm{b}}=A I^{B}$, where $A=5 \cdot 10^{-6}$ and $B=0.62$ for all particle sizes.

In this study, particles were released from the observation sites at a constant rate of 15000 particles per hour during every measurement sampling interval and followed backwards in time for 20 days. Given the limited number of measurement samples available (in total 17000), this backward mode is computationally much more efficient than calculating transport forward in time from the large number of individual source elements $(360 \times 180$ spatial grid cells with $8 \times 365$ releases per year for each 4 size-class of aerosol). For a linear problem like this, forward and backward simulations are equivalent and yield the same results, except for small numerical and interpolation errors (Seibert and Frank, 2004). Another advantage is that no source information is needed to run FLEXPART backward in time. Instead, the source information is added in a post-processing step, such that all SSA source functions can be tested with one and the same model simulation. The simulation period of 20 days is several times the residence time of SSA particles in the lower troposphere. Tests with longer simulation periods yielded results that were within $1 \%$ of those obtained with 14 days. This means that sea salt older than 14 days contributes very little to the simulated SSA concentrations at the chosen receptor sites.

For selecting the particle sizes of the simulated lognormal modes, consideration was primarily given to the particles' lifetime. For accumulation-mode particles, gravitational settling is minimal and thus the accumulation-mode particles all have relatively similar lifetimes in FLEXPART, although dry deposition does depend on particle size. For particles larger than about $D_{\mathrm{p}}=4 \mu \mathrm{m}$ at $80 \% \mathrm{RH}$, gravitational settling becomes increasingly important with size, and so has to be differentiated more finely. By performing tests with many more size classes, it was found that differentiating size classes below $\sim 4 \mu \mathrm{m}$ gives little extra information because FLEXPART simulates both the transport and removal of all of these particles very similarly. Four lognormal distributions with modal radii $r=0.65,4.7,6.8$ and $8.9 \mu \mathrm{m}$ and corresponding standard deviations $\sigma=1.35,1.1,1.075$ and 1.05 respectively were chosen to approximate all the source functions. These four distributions were chosen based on multiple model runs with aerosols of up to 20 different particle size distribution modes, in order to best capture the model differences between the different sizes of SSA.

The output of FLEXPART tracing mass concentrations in backward mode is an emission sensitivity expressed in seconds and given as a function of space (at $1^{\circ} \times 1^{\circ}$ and variable vertical resolution) and time (every $3 \mathrm{~h}$ ). Multiplying the 
emission sensitivity in the lowest model layer, taken here as $100 \mathrm{~m}$, which is the minimum boundary layer height used in FLEXPART with a source flux, gives so-called source contributions. Integrating these source contributions over all grid cells and $3 \mathrm{~h}$ intervals then gives the simulated SSA concentration at the measurement point averaged over the measurement sampling interval. In this configuration, different SSA source functions can be tested very efficiently. For more information on the FLEXPART backward mode and how it can be used for evaluating emissions, see Seibert and Frank (2004) and Stohl et al. (2003, 2009).

In addition to the emission sensitivity, a number of other variables were recorded for the footprint area to allow for the examination of the factors determining the SSA production, namely time-resolved source region wind, temperature and salinity averages and frequency distributions, together with total emission sensitivity over the ocean only. The averages were area- and time-weighted by the emission sensitivity. This allows for a detailed examination of the influence of temperature, wind and salinity on SSA production.

The color shading in Fig. 4 represents the measurement network's average footprint emission sensitivity, a measure of how well sea areas are characterized by the sampling network. The map shows that most of the ocean surface is well covered with representative observations, but the tropics are less well-covered than higher-latitude regions.

\section{Results and discussion}

\subsection{A case study}

For each aerosol sample and station, emission sensitivities were calculated with FLEXPART in backward mode according to the method described in Sect. 4. The emission sensitive area for one sample is illustrated in Fig. 5a where red colored areas indicate where a unit emission would have the strongest influence on aerosol loading. Typically, areas closest in time and space to the observation have the highest footprint emission sensitivity, as all measurements were sampled near the surface and as dispersion distributes the emission sensitivity over larger areas further back in time. Furthermore, removal processes reduce the emission sensitivity and descending air masses may also lose contact with the ocean surface with backward time. Actual emission contributions to the total modeled SSA concentration are given by the product between the emission flux and the emission sensitivity. Thus, highest SSA contributions to the modeled concentration occur in grid cells where both the emission sensitivity and the emission flux are high. The emission flux at each location in time and space was calculated according to the local wind speed and temperature. Figure $5 \mathrm{~b}$ shows the spread of the resulting modeled concentrations compared to the measured concentrations for all the samples taken during the cruise ICEALOT in the North Atlantic. Pearson's correla- tion coefficients ("Pearson's $r$ ") for the different source functions range from 0.57 to 0.77 for the 52 samples taken during the cruise. While correlations are fairly good for all source functions, modeled concentrations obtained by applying the different source functions can have large relative biases (calculated as (model-observed)/observed), i.e., from $-78 \%$ to several $100 \%$ when compared to modeled aerosol particles with $D_{p}<8 \mu \mathrm{m}$.

In Fig. $5 \mathrm{c}$ the source region characteristics in terms of total oceanic footprint emission sensitivity, wind speed, and temperature for each sample are shown. As can be seen from Fig. 5c, the samples taken during the ICEALOT cruise have emissions from waters with mean wind ranging from about 3 to $15 \mathrm{~m} \mathrm{~s}^{-1}$ and SSTs in the range from -2 to $17^{\circ} \mathrm{C}$. These data will be subsequently used to evaluate under which conditions particular source functions yield accurate results, and under which conditions they fail to predict the observed concentrations.

In addition to the shown mean characteristics, additional data are available. Although the focus of our analysis has been on wind speed and temperature, information on sea ice and the fraction of coastal water area as well as frequency distributions of all parameters are available for all observations. While we searched for possible influences of sea ice and coastal water fractions, no statistically significant relationships were found, and thus these parameters are not discussed further.

\subsection{Production estimates}

In Fig. 6 the frequency distribution of the oceanic $3 \mathrm{~h}, 1^{\circ} \times 1^{\circ}$ $10 \mathrm{~m}$ wind speeds is shown with gray bars. The most frequent wind speeds are $5-7 \mathrm{~m} \mathrm{~s}^{-1}$ with a long-tailed distribution towards higher wind speeds. Using the wind dependence of the source functions shown in Fig. 2, the annually produced mass at each wind speed in the frequency distribution was calculated. As can be seen in Fig. 6, the SSA production frequency distribution is shifted to higher wind speeds compared to the frequency distribution of the wind itself, as stronger winds produce more sea salt. The maximum annual SSA mass is produced for winds in the range $7-16 \mathrm{~m} \mathrm{~s}^{-1}$, depending on the parameterization chosen. Source functions that have about the same estimate of global annual mean SSA generation can produce the largest aerosol mass at quite different wind speeds, resulting in different temporal and spatial distribution of the SSA. From the small differences in global production between different years ( \pm in Table 2 ) for a given source function, it is clear that variability in global annual average wind does not explain the large differences between the SSA mass produced by the different source functions.

Most of the source functions have been used with largescale models, but not all have previously been used to calculate global emission totals. Here SSA production was calculated for each source function over a $25 \mathrm{yr}$ period using the ECMWF wind fields. Annual mean global SSA production 


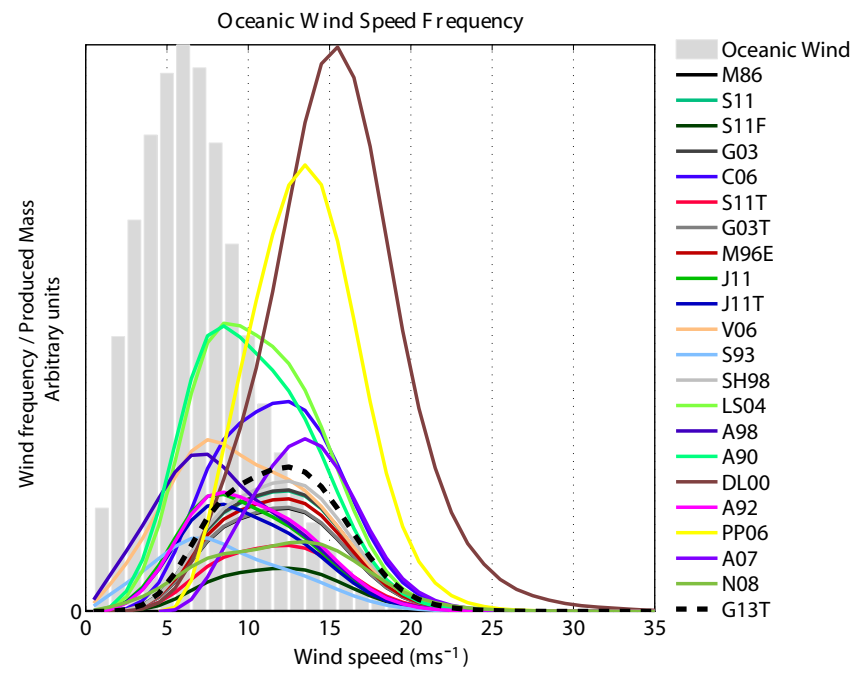

Fig. 6. Histogram of global oceanic $3 \mathrm{~h}, 10 \mathrm{~m}$ wind speed $U_{10}$ in the $25 \mathrm{yr}$ of ECMWF data (gray bars) used to calculate SSA production. The resulting mass globally produced at each wind speed is obtained by accounting for the wind dependencies of production in Fig. 2 for the 22 different source functions (colored curves). The total area under each curve is the logarithm of the total mass produced annually by each function.

for the source functions is reported in Table 2, with values spanning the range of 1.83 to $2444 \mathrm{Pg} \mathrm{yr}^{-1}$. The global distribution of the $8.9 \mathrm{Pgyr}^{-1}$ produced by G13T is shown in Fig. 7 (top left) in units of $\mathrm{kg} \mathrm{km}^{-2} \mathrm{yr}^{-1}$. The interannual variability $( \pm 0.61)$ is small compared to the global mean production and no significant trend was found in either the annually produced mass or mean $10 \mathrm{~m}$ wind.

For the most widely used source function, M86, published global fluxes reported in the literature range from 3.3 to 11.7 $\mathrm{Pg} \mathrm{yr}^{-1}$ (Lewis and Schwartz, 2004), with at least seven published estimates in between. These different estimates can largely be explained by differences in the models' surface wind and in part by differences in model resolution. It is interesting to notice that one source function such as M86 can yield such different annual estimates when considering the same sizes of aerosol. The result in this study of $4.5 \mathrm{Pg} \mathrm{yr}^{-1}$ for M86 in Table 2 is in the lower range of estimated annual production rates for M86.

For the G03 source function, the global production found here for $D_{\mathrm{p}}<10 \mu \mathrm{m}$ is $4.6 \mathrm{Pgyr}^{-1}$. This is the same as that found in Jaeglé et al. (2011), but for a smaller size range, $D_{\mathrm{p}}<5 \mu \mathrm{m}$. The fraction of the mass of the particles larger than $<5 \mu \mathrm{m}$ in G03 is about $30 \%$, meaning that for the same size range, about $30 \%$ less is produced with the ECMWF winds than with the GEOS-5 winds used by Jaeglé et al. (2011). For S11T, the annually produced mass in our study is $2.6 \mathrm{Pg} \mathrm{yr}^{-1}$, about one third of the value reported in Sofiev et al. (2011) for the temperature weighted function. The original function proposed with no temperature or salinity weights, however, gives only slightly lower values here (5.9 $\left.\mathrm{Pg} \mathrm{yr}^{-1}\right)$ compared to theirs $\left(6.7-7.4 \mathrm{Pg} \mathrm{yr}^{-1}\right)$. The reason for this is that the annual produced mass as reported in Sofiev et al. (2011) are actually not for the temperature-weighted function (M. Sofiev, personal communication, 2013), but rather for the un-weighted source function. Applying the temperature weight reduces the produced mass, and S11F and S11T have the lowest production of all source functions.

The LS04 source function yields one of the largest global SSA emissions with $73 \mathrm{Pg} \mathrm{yr}^{-1}$. This value is far outside of the range given by Lewis and Schwartz (2004), i.e., 1.2$20 \mathrm{Pg} \mathrm{yr}^{-1}$. Here it should be noted that we have extrapolated the wind-speed range to values below $5 \mathrm{~m} \mathrm{~s}^{-1}$ which was the lower bound in the estimated wind dependency by LSO4, and this adds about $10-15 \%$ to global production. However, this does not explain the large value obtained.

The V06 function has a larger production than most source functions for particles $D_{\mathrm{p}}>1 \mu \mathrm{m}$ at medium to high winds especially, which results in larger-than-average production. The by far biggest estimate is obtained with the DL00 function. This is a SSA source function meant to describe coastal production and is not really suitable to estimate global production. It was included in this paper as an example of a source function with very high wind dependency in production. Global SSA production rates of most of the remaining source functions are in the interval 4-10 $\mathrm{Pg} \mathrm{yr}^{-1}$.

\subsection{Global correlations}

The correlations between FLEXPART modeled and observed SSA concentrations are listed in Table 2. The correlations are given for the entire data set $\left(r_{\mathrm{a}}\right)$ and also for the data subsets $\mathrm{PM}_{10}$ measurements $\left(r_{\mathrm{PM}_{10}}\right)$, EMEP stations $\left(r_{e}\right)$ and the weekly observations $\left(r_{\mathrm{W}}\right)$. For the columns $r_{\mathrm{W}}, r_{\mathrm{PM}_{10}}$ and $r_{e}$, we report values that were first calculated per station and then averaged. For the column $r_{\mathrm{a}}$ in Table 2, it is the correlation to the data set as a whole.

The correlation for the ICEALOT cruise is somewhat better than the mean correlation for the $\mathrm{PM}_{10}$ measurements, and similar to the EMEP measurements (as reported in Table 2). Sampling sectors were used within the SEAREX, AEROCE and DOE networks, and also at the two NOAA stations, so a sample from these stations does not necessarily represent the average SSA concentration for the period of measurement. This is the main reason for the model not being able to accurately represent the values of many of the weeklong $\left(r_{\mathrm{W}}\right)$ observations. As shown in Table 2, $r_{\mathrm{W}}$ values are lowest. These difficulties with the weekly observations also lead to very low grand total correlation values $r_{\mathrm{a}}$. Our interpretation of the results is therefore mainly based on the $\mathrm{PM}_{10}$ and EMEP correlations.

The overall best correlation is obtained with the source function proposed in this study (G13T). Looking at the wind dependencies of the functions it is clear that the functions 

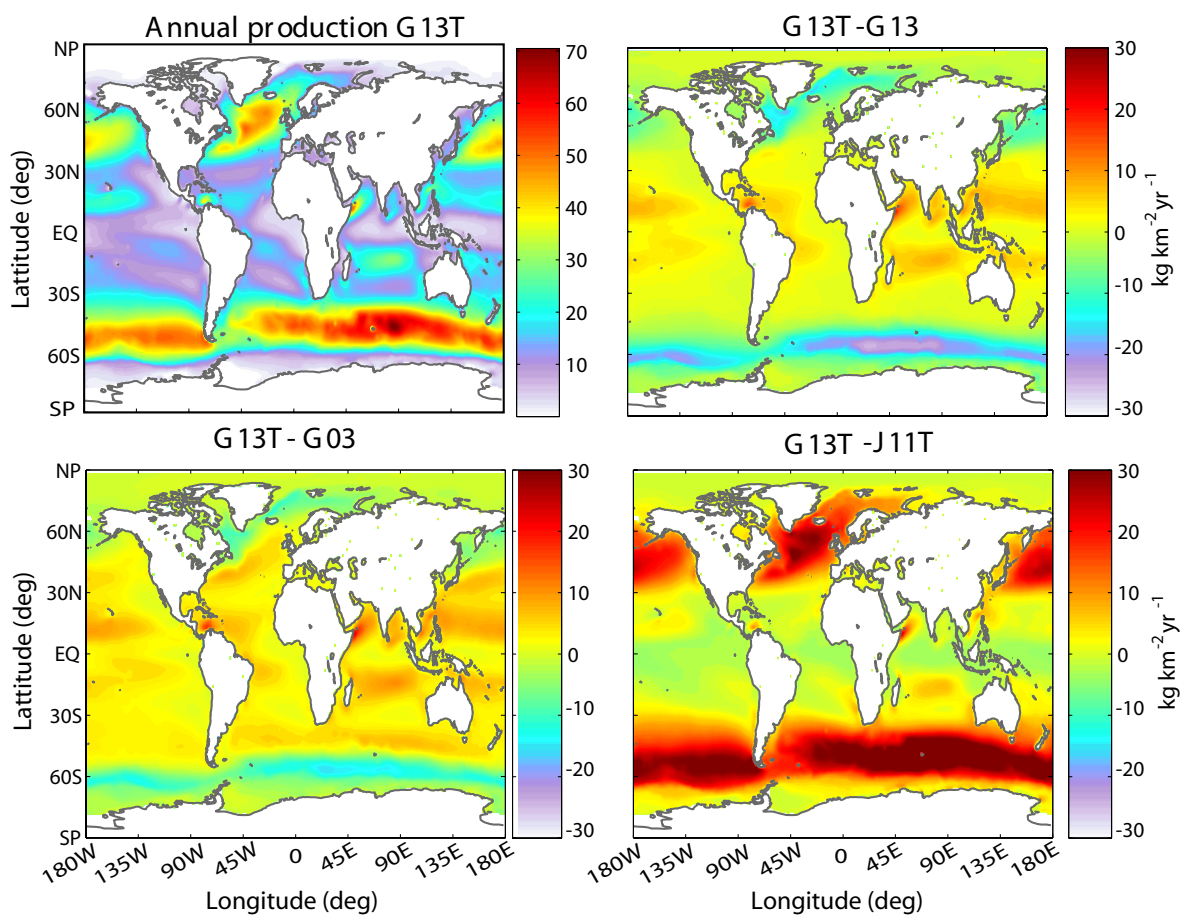

Fig. 7. Top left: annual global production for the new source function G13T. Top right: the difference in global annual production when taking into account the temperature influence (G13T) and when ignoring temperature influence (G13) for the new source function. Bottom left: the difference between G13T and G03. Bottom right: the difference between G13T and J11T. For acronyms in the legend, see Table 1.

that have a relatively high wind-speed dependence of the production obtain the highest correlations with the measurement data for individual networks and stations (up to $r=0.86$ for individual EMEP stations). The applied temperature functions do not improve model performance significantly in comparison to any of the data subsets. However, when combining all the data, a clear improvement is evident for all the functions with a temperature dependence in production. For instance, $r_{\mathrm{a}}$ increases from 0.26 for $\mathrm{J} 11$ to 0.41 for J11T. This is because the stations are located in different temperature regimes and the range of temperatures occurring for any of the data subsets is not large enough to reveal a temperature dependence of SSA production. However, the temperature dependence emerges for the combined data set.

The correlations between modeled and observed SSA concentrations are comparable to the values reported in other studies (Jaeglé et al., 2011; Sofiev et al., 2011; Tsyro et al., 2011) for the source functions used. This shows that the FLEXPART model performance is comparable to "state of the art" Eulerian aerosol models.

\subsection{Aerosol production biases and an estimate for the global SSA production}

Values of the relative bias ((model-observed)/observed) between FLEXPART modeled and observed concentrations for comparison between all the EMEP and NOAA $\mathrm{PM}_{10}$ ob- servations and modeled concentrations, expressed in $\%$, are reported in Table 2 in the column labeled "Bias". All the most frequent wind conditions (with wind speeds $U_{10}<\sim$ $18 \mathrm{~m} \mathrm{~s}^{-1}$ ) are well covered, and observations from all regions and conditions included, though there are more samples from colder temperatures for this subset of the data. There is no single SSA source function that consistently gives the smallest bias for all the data subsets, but different functions yield the smallest relative biases to the observed concentrations in the different data subsets.

Figure 8 shows the global annual SSA mass production from the various source functions plotted against their relative bias towards the measured concentrations. A linear least squares fit of the annual produced mass and model bias intersects the zero bias value at $10.2 \mathrm{Pg} \mathrm{yr}^{-1}$. The result of this linear fit is more strongly influenced by the large annual estimates than the smaller estimates, and thus DL00, an outlier that clearly gives too-high SSA production, was excluded from these calculations.

When making comparisons with the EMEP observations only, the estimate would be $10.8 \mathrm{Pg} \mathrm{yr}^{-1}$. Based on the NOAA data only, the intersection would be at $9 \mathrm{Pgyr}^{-1}$. The EMEP observations, however, include observed particles that are larger than what is included in the production (see Sect. 3). Thus this may be considered an upper estimate for the annual global SSA production for $D_{p}<10 \mu \mathrm{m}$. An estimate of annual SSA production based only on the 


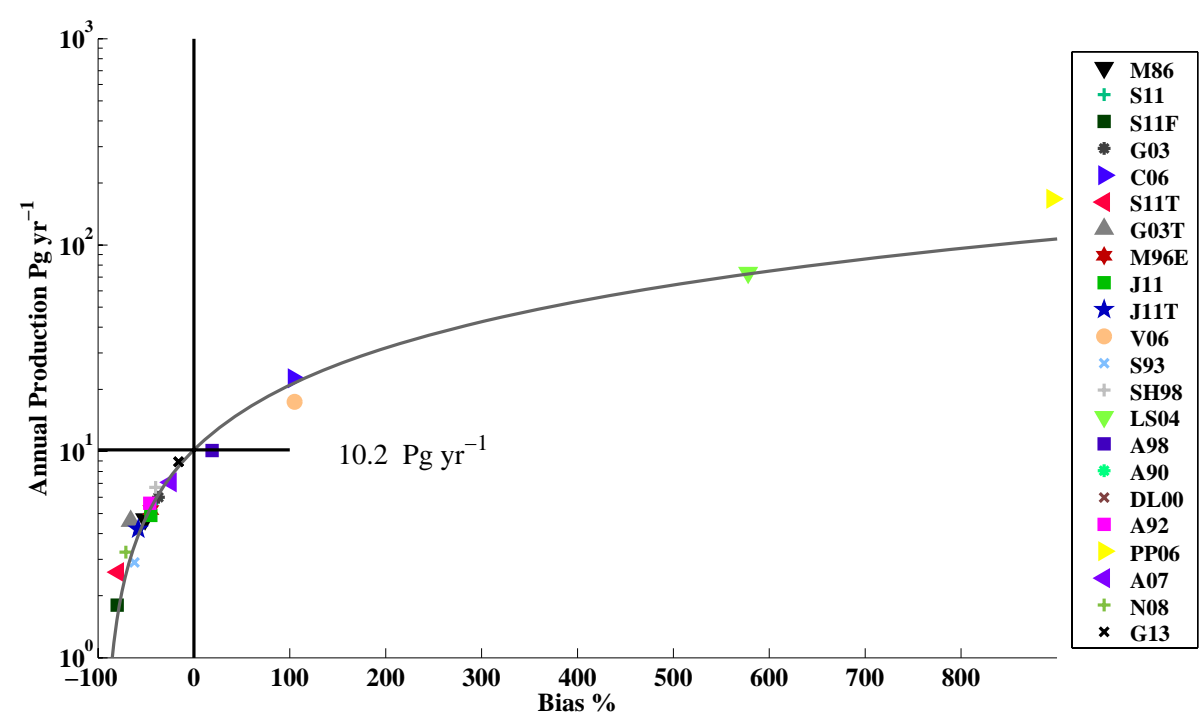

Fig. 8. Global annual SSA mass production plotted against the bias of modeled vs. observed PM $_{10}$ and EMEP concentrations. The fitted curve is the first-order linear fit to the data. The intersection of the fitted curve with the zero bias line yields a best estimate of global annual $\mathrm{PM}_{10}$ emissions of $10.2 \mathrm{Pg} \mathrm{yr}^{-1}$. DL00 is outside the plotted range. For acronyms in the legend, see Table 1.

EMEP measurements is furthermore not fully representative of global conditions, since all the EMEP stations are located near the northern Atlantic (Fig. 4), but combined with the NOAA $\mathrm{PM}_{10}$ data we have good global coverage. Since the NOAA data has a smaller cut-off than $D_{\mathrm{p}}=10 \mu \mathrm{m}$, it can be argued that the average cut-off of the combined NOAA and EMEP data sets would be close to $D_{\mathrm{p}}=10 \mu \mathrm{m}$. Thus our best estimate is $10.2 \mathrm{Pg} \mathrm{yr}^{-1}$, with a range of uncertainty regarding what sizes are included in measurements of 9$10.8 \mathrm{Pg} \mathrm{yr}^{-1}$. The new source function has an annual production of $8.9 \mathrm{Pg} \mathrm{yr}^{-1}$, on the lower side of this estimate.

Considering only the weekly TSM measurements, the global estimate would, however, increase to $36 \mathrm{Pg} \mathrm{yr}^{-1}$, and for the entire set of data (including NOAA and EMEP), we obtain $29 \mathrm{Pg} \mathrm{yr}^{-1}$. The reason for basing the estimate on the $\mathrm{PM}_{10}$ and EMEP measurements only is that for the remaining observations an approximate upper limit of the aerosol particle size cannot be calculated. There is also reason to believe that there are a number of stations that are somewhat influenced by a local surf zone and thus may be biased in terms of total mass due to high mass loadings of locally produced large aerosol. For the other purposes these data are used for in this paper (i.e., wind and temperature dependence), this is not such a significant problem, at least not if the surf zone contribution is similar for all SSA sizes and wind/temperature conditions.

\subsection{Wind-speed dependence}

To investigate the differences between source functions at different wind speeds, the emission sensitivity weighted, source average wind speed (as shown in Fig. 5c) was used for each sample. In order to use data from all stations and only look into the wind dependence, all observations and model concentrations $\left(x_{i}\right)$ were normalized as $x_{\mathrm{n}}=x_{i} / \bar{x}$, where $x_{\mathrm{n}}$ is the normalized concentration and $\bar{x}$ the average concentration for each individual station. This normalization was done to reduce any biases caused by differences in measurement techniques, and to reduce the influence of interstation temperature differences. The observed and modeled concentrations were then plotted against the emission sensitivity weighted source average wind speed. Notice that while the source area wind was averaged to characterize each sample with a "typical" wind, the model simulations fully accounted for the variable wind conditions encountered by each air mass as it moved to the receptor point. For clarity of presentation, we do not show here scatter plots of all data points and for all source functions. Instead we perform a secondorder polynomial least-squares fit through the data for each individual source function to summarize the modeled windspeed dependencies of the various source functions (Fig. 9). Only source average wind speeds up to $16 \mathrm{~m} \mathrm{~s}^{-1}$ were considered for Fig. 9 because of a lack of data for higher wind speeds.

The observed increase in relative concentrations with source-region averaged wind speed is close to $U_{10}^{2}$. Dry deposition is more efficient in strong winds, which means that both production as well as loss of SSA increase with wind speed. This makes the relationship between wind and concentration weaker than that of the production. Closest to the observed relationship are the G13T and SH98 source functions, with $U_{10}^{3.5}$ as the SSA production wind dependence. Note, however, that G13T also has a temperature dependence that distinguishes it from SH98. DL00 and N08 clearly produce too much SSA in high wind conditions, and are in 


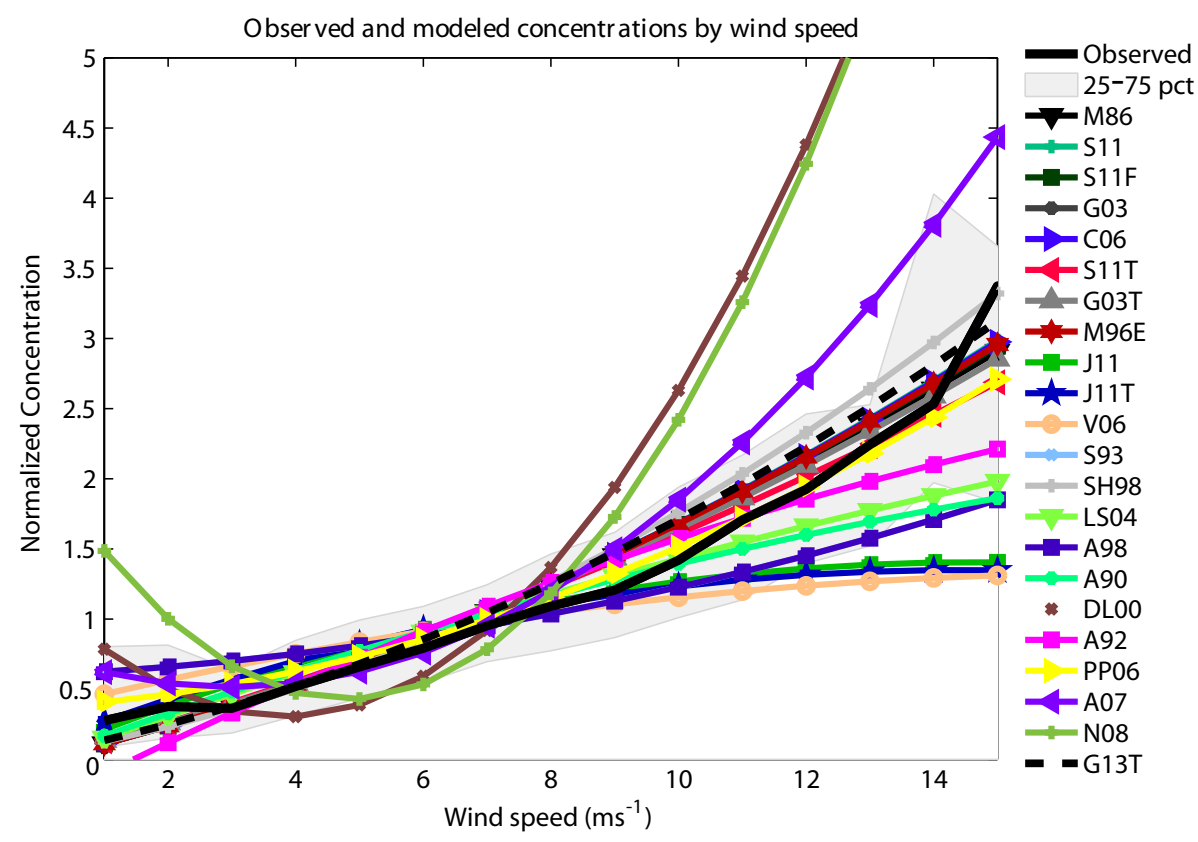

Fig. 9. Median-normalized measured and modeled SSA concentrations as a function of source-region average wind speed. Observations are shown by a black solid line with the grey shaded area giving the $25-75 \%$ range. Colored lines are modeled values (for acronyms in the legend, see Table 1) approximated with a second-order polynomial fit.

disagreement with the observations. The increase of SSA concentrations towards low wind speeds for DL00 and N08 in Fig. 9 is an artifact of the polynomial fit. Note, however, that for Fig. 9 the wind is averaged over the wind-speed distribution encountered in the source area, although the SSA production cannot strictly be described by a single value for the wind speed because it is not linearly dependent on the wind. This is the reason why, even at very low source average wind speeds, both the observed and the modeled SSA concentrations can be substantial. It is also worth noting that the source functions that are available both with and without temperature dependence (i.e., S11 \& S11T and J11 \& J11T) show slight differences in concentrations at different wind speeds because wind and temperature are not independent.

The difference in global annual production between G13T and two source functions, G03 and J11T, is shown in Fig. 7 (bottom). The source function G03 has a slightly lower wind dependence than G13T, while J11T has the lowest wind dependence of all SSA functions (see Fig. 2). Because the annual global mass production of G13T is largest $\left(8.9 \mathrm{Pg} \mathrm{yr}^{-1}\right)$ more SSA is produced in most areas. Differences are, however, most prominent in regions of high wind, where J11T has very little production and G03 more compared to G13T. That G03 has the relatively highest production in strong wind areas is related to the temperature dependence of G13T. Areas of strong annual average winds generally have SSTs below average and thus the production of G13T is reduced by the negative temperature dependence.
In the case of G13T-J11T, the spatial differences are due to the difference in the dependence of production on wind, while for G13T-G03 most of the difference is due to the fact that G13T takes the effect of temperature into account and thus particularly decreases the SSA generated in the highly productive region around Antarctica.

\subsection{Temperature dependence}

The influence of temperature is examined in the same way as the influence of wind, except that $x_{\mathrm{n}}$ is normalized to the mean of the entire set of data rather than to the mean of each individual station in order to capture interstation temperature differences. To prevent a too-strong influence of the correlations between wind speed and temperature dependencies (other than taken into account by the source functions), data were used only for source average wind speeds between 5 and $10 \mathrm{~m} \mathrm{~s}^{-1}$. Linear fits through the data were made for the model results using the different source functions. For clarity of presentation, only these linear fits are shown in Fig. 10. Observed SSA mass concentrations clearly increase with increasing source average temperatures, and this increase is even slightly stronger for wind speeds above $10 \mathrm{~m} \mathrm{~s}^{-1}$ (not shown). For the wind-speed range $5-10 \mathrm{~m} \mathrm{~s}^{-1}$, the linear dependence in observed concentration is

$\mathrm{SSA}=0.031 T+0.39$.

This strong increase of SSA production with temperature adds to the findings of Sofiev et al. (2011) of a too-thin marine aerosol optical depth in the tropics. It also supports the 


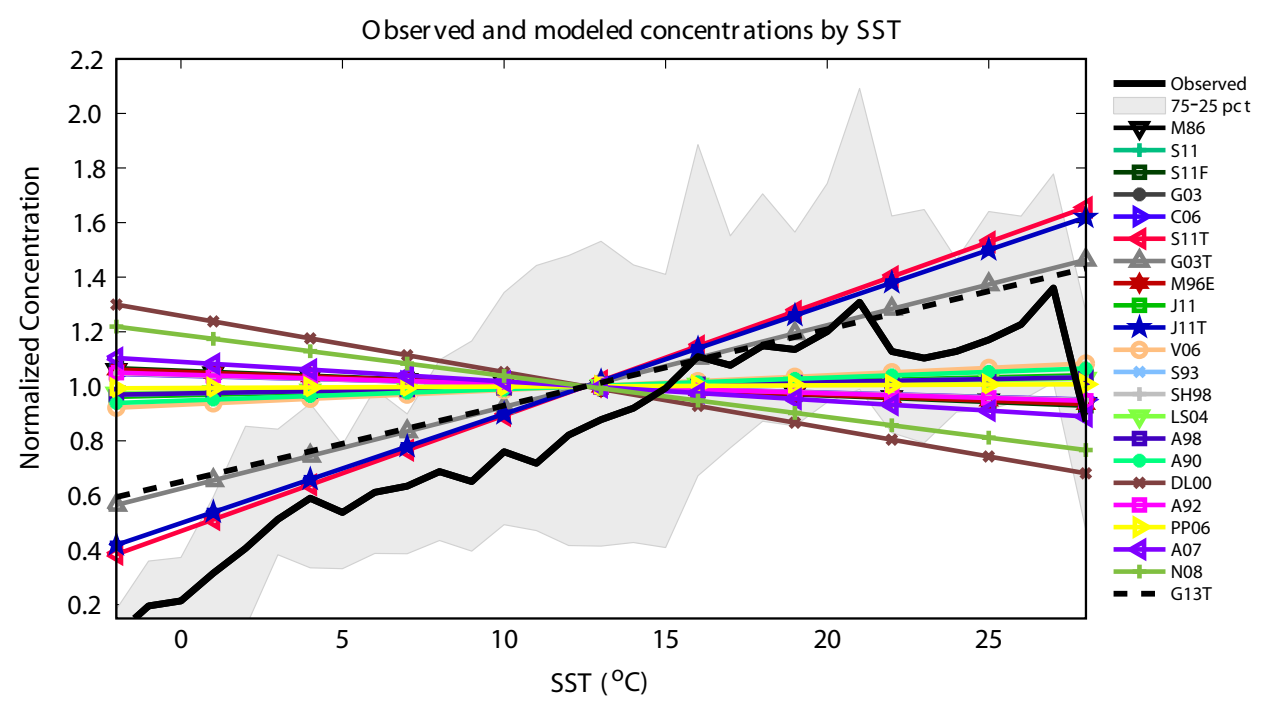

Fig. 10. Same as Fig. 9, but for source-region average temperature and with a first-order polynomial fit for the source functions. Data points were used only when the source average wind was in the range $5-10 \mathrm{~m} \mathrm{~s}^{-1}$ (for acronyms in the legend, see Table 1).

finding of Jaeglé et al. (2011) that adding a temperature dependence to SSA source functions is a better method to address model tropical underestimation than reducing a source function's wind dependency. In regions of high SST, such as the tropics, winds are generally low (Fig. 3). Thus, for source functions with the same global SSA mass production, a lower wind dependence means that relatively more mass is produced in the low-wind areas such as the tropics. However, the correlations between modeled and observed concentrations are best for the source functions with comparably strong wind dependence, and a low wind dependence does not provide a good fit to the observational data. In Fig. 7 (top right) the equatorward shift in SSA production can be observed by taking into account the temperature dependence with Eq. (10). It is not a uniform shift, but the difference of SSA production is amplified by the wind speed. As seen in Fig. 7 (bottom right), where J11T has the same temperature dependence as G13T but a lower wind dependence, the mass produced by $\mathrm{J} 11 \mathrm{~T}$ outside the tropics is significantly lower than that of G13T; however, this does not fit the observations (Table 2).

It is worth noting that there is not a $1: 1$ relationship between increase in production and the increase in concentrations shown in Fig. 10. This is due to the nonlinearity of the two existing SST functions applied (Eqs. A7 and A4), winds not being evenly distributed with SST and that more data are available for temperatures lower than $20^{\circ} \mathrm{C}$. The source functions G13T, S11T, G03T and J11T incorporate a temperature dependence that matches the observed concentration increase with temperature very well (Fig. 10). Though there are small differences, Eq. (A7) was found to give the best improvement to the correlation of G13 and was therefore used. Some of the remaining functions' SSA mass concentrations also show a weak temperature dependence despite not explicitly including it, which is due to a slightly skewed wind distribution with temperature within the wind-speed range considered $\left(5-10 \mathrm{~m} \mathrm{~s}^{-1}\right)$. Because of this wind distribution, the SSA source functions that have a strong dependence of production on the source wind have a slightly negative slope.

There are large uncertainties in the results related to the temperature dependence of SSA production tied to the heterogeneity of the observational data. Since the result is simply based on the relationship between temperature and concentration for the whole data set, other compounding factors such as the distance of the measurement location from the coast, altitude and type of measurement are not considered. Especially, the two northernmost stations, Zeppelin and Barrow, are at $476 \mathrm{~m}$ altitude and at $3 \mathrm{~km}$ distance from the coast, respectively, so the low SSA concentrations measured at these stations are strongly influenced by these factors. Nonetheless, with the vast amount of data collected no single station shifts the temperature relationship significantly and the apparent strong temperature influence is prominent even in subsets of the data.

\section{Conclusions}

The novelty in this study lies in the source-receptor relationships applied for SSA. While earlier studies have used local wind speeds and temperatures to connect SSA production and concentration, this study has used wind speed and temperature data from the area where the aerosols are actually produced and should therefore be more accurate. These production areas were identified using backward modeling with a Lagrangian particle dispersion model. This also facilitated the application and comparison of 21 different source 
functions as well as the establishment of a new source function that depends on wind and temperature and which is in best agreement with global SSA concentration data. Our main conclusions from this study are the following:

- Correlations between measured and modeled SSA concentrations are much lower $(r=0.22-0.54)$ at stations that apply wind-sectored sampling than at stations with unconditional sampling $(r=0.36-0.86)$. This demonstrates that data obtained with sectored sampling are very difficult to use for quantitative analyses as the measurements do not represent a timemean concentration. Quantitative comparisons between measurements and model results are thus highly uncertain for these stations.

- Several of the reviewed source functions were incompatible with observations, both in terms of correlation and bias between observed and modeled SSA mass concentrations. These source functions should not be used for global modeling studies.

- For the EMEP stations, correlations between measured and modeled SSA concentrations range from $r=0.42$ to 0.81 . The best-performing SSA production function with the best correlation between modeled and measured SSA concentrations is the new source function G13T (up to $r=0.86$ for individual EMEP stations). Also, G13T has the smallest bias (6\%), whereas biases for the other source functions range from $-78 \%$ to several thousand $\%$.

- Wind speeds in the range 5-14 $\mathrm{ms}^{-1}$ are very frequent and are responsible for about $80 \%$ of the global SSA production. It is therefore especially important that parameterizations of SSA production accurately capture the wind-speed dependence in this wind-speed range. A power law dependence where SSA production is proportional to $U_{10}^{3.5}$ was found to best describe the observed SSA concentrations.

- We found a clear dependence of SSA production on SST, although the physical mechanisms driving this dependence are not understood. Nevertheless, temperature dependence needs to be taken into account for a globally valid SSA source function. This temperature dependence is particularly important for explaining the relatively high SSA concentrations found in the tropics. SSA concentrations increase with temperature according to the relationship $0.031 T+0.39$ for winds between $5-10 \mathrm{~ms}^{-1}$. For all winds the best model fit to observations was found by using Eq. (A7) of Jaeglé et al. (2011) with G13 (G13T).

- Estimates of the atmospheric SSA aerosol burden have a larger uncertainty than burden estimates for all other aerosols combined (Textor et al., 2006). This is reflected by the large spread of more than $70 \mathrm{Pg} \mathrm{yr}^{-1}$ between the "best" SSA source functions found in this work. The reasons for these large differences between the source functions are not apparent, but may be related to the type of measurements from which the various source functions have been derived. The global annual budget of SSA is thus strongly dependent on the choice of the source function.

- The new source function G13T has an annual SSA production rate of $9 \mathrm{Pg} \mathrm{yr}^{-1}$ with interannual variability of $\pm 0.61 \mathrm{Pg} \mathrm{yr}^{-1}$. Based on a comparison of modeled and measured SSA concentration, a best fit to the observed concentrations would be $10.2 \mathrm{Pg} \mathrm{yr}^{-1}$ with an uncertainty range of $9-10.8 \mathrm{Pg} \mathrm{yr}^{-1}$.

\section{Appendix A}

\section{Sea-spray aerosol source functions}

Monahan and O'Muircheartaigh (1980) suggested, based on photographic evidence, that the fraction of the sea surface that is covered by white water $(W)$ is dependent on the $10 \mathrm{~m}$ wind speed and follows the power law

$W_{M}\left(U_{10}\right)=3.84 \cdot 10^{-6} U_{10}^{3.41}$.

\section{A1 M86 \& M86E}

A size-dependent SSA flux with this wind dependence was suggested by Monahan et al. (1986):

$$
\frac{\mathrm{d} F}{\mathrm{~d} D_{\mathrm{p}}}=W_{M} \cdot 3.6 \cdot 10^{5} D_{\mathrm{p}}^{-3}\left(1+0.057 \cdot D_{\mathrm{p}}^{1.05}\right) \cdot 10^{1.19 \exp \left(-B^{2}\right)},
$$

where

$$
B=\frac{0.38-\log \left(D_{\mathrm{p}}\right)}{0.65} \text {. }
$$

This is referred to as MM86, and MM86E is the function extrapolated to be valid for $D_{\mathrm{p}}=0.1-10 \mu \mathrm{m}$.

\section{A2 S11 \& S11T \& S11F}

Sofiev et al. (2011) proposed an effective flux that is not only dependent on the wind speed, but also on the $\operatorname{SST}(T)$ and salinity $(S)$ of the water.

$$
\begin{aligned}
& \frac{\mathrm{d} F}{\mathrm{~d} D_{\mathrm{p}}}=W_{M} \cdot T_{\mathrm{W}} \cdot S_{\mathrm{W}} \cdot 10^{6} \cdot \frac{\exp \left(\frac{-0.09}{D_{\mathrm{p}}+3 \cdot 10^{-3}}\right)}{2+\exp \left(-\frac{5}{D_{\mathrm{p}}}\right)} \cdot \frac{1+0.05 D_{\mathrm{p}}^{1.05}}{D_{\mathrm{p}}^{3}} \\
& \cdot 10^{1.05 \exp \left(-\left(\frac{0.27+\log \left(D_{\mathrm{p}}\right)}{1.1}\right)^{2}\right)} .
\end{aligned}
$$


Here, $T_{\mathrm{W}}$ is applied as

$T_{\mathrm{W}}\left(T_{i}, D_{\mathrm{p}}\right)=a_{i} D_{\mathrm{p}}^{b_{i}}$

where

$$
\begin{aligned}
T_{i} & =[25,15,5,-2] \\
a_{i} & =[1,0.48,0.15,0.092] \\
b_{i} & =[0,-0.36,-0.88,-0.96] .
\end{aligned}
$$

Here $T_{\mathrm{W}}$ is the temperature dependence of production at a temperature $T_{i}$. Since Eq. (A4) is only given for the temperatures listed, the corresponding coefficients $a_{i}$ and $b_{i}$ were linearly interpolated between the temperatures as suggested by Sofiev et al. (2011). Eq. (A3) is $\mathrm{S} 11$ with $T_{\mathrm{W}}=1$, but for $\mathrm{S} 11 \mathrm{~T}$ the temperature weight is used and inter- and extrapolated as suggested by Sofiev et al. (2011). S11F is for a sea surface temperature of $15^{\circ} \mathrm{C}$, as used in Sofiev et al. (2011). The salinity weight proposed by Sofiev et al. (2011) is not applied in this study.

\section{A3 G03}

Gong (2003) suggested that the size-dependent flux of aerosol be represented by a proposed tuning parameter $\Theta$ which is set to $\Theta=30$ and referred to as $\mathrm{G} 03$ :

$\frac{\mathrm{d} F}{\mathrm{~d} D_{\mathrm{p}}}=W_{M} \cdot 3.6 \cdot 10^{5} D_{\mathrm{p}}^{-A}\left(1+0.057 \cdot D_{\mathrm{p}}^{1.05}\right) \cdot 10^{1.19 \exp \left(-B^{2}\right)}(\mathrm{A} 5)$

where

$$
\begin{aligned}
A & =4.7\left(1-\Theta D_{\mathrm{p}}\right)^{-0.017 D_{\mathrm{p}}^{-1.44}} \\
B & =\frac{0.433-\log \left(D_{\mathrm{p}}\right)}{0.433} .
\end{aligned}
$$

\section{A4 C06}

Clarke et al. (2006) (C06) estimated the SSA production flux as

$$
\begin{aligned}
& \frac{\mathrm{d} F}{\mathrm{~d} \log D_{\mathrm{p}}}=W_{M} \sum_{i=1}^{3} \beta_{i, 0}+\beta_{i, 1} D_{\mathrm{p}}^{1} \\
& +\beta_{i, 2} D_{\mathrm{p}}^{2}+\beta_{i, 3} D_{\mathrm{p}}^{3}+\beta_{i, 4} D_{\mathrm{p}}^{4}+\beta_{i, 5} D_{\mathrm{p}}^{5} .
\end{aligned}
$$

For values of the $\beta$ coefficients, see Clarke et al. (2006).

\section{A5 G03T, J11 \& J11T}

Jaeglé et al. (2011) introduced an empirically based temperature weight, which increases SSA production for warmer SST:

$T_{\mathrm{W}}(T)=0.3+0.1 T-0.0076 T^{2}+0.00021 T^{3}$.

This is applied to G03 to make G03T. Jaeglé et al. (2011) also suggest exchanging $W_{M}$ in $\mathrm{G} 03$ with

$W_{J}\left(U_{10}\right)=25.5 \cdot 10^{-6} U_{10}^{2.07}$.
Using $W_{J}$ with G03 is thus denoted J11 and J11T, with and without the temperature weight, respectively.

The following distribution and wind dependency was proposed by Vignati et al. (2001):

$$
\begin{aligned}
& \frac{\mathrm{d} F}{\mathrm{~d} r_{80}}=10^{0.095 U_{10}+0.283} \sqrt{3.8 \pi} \exp \left(\frac{r_{80}-0.2}{2 \log 1.9}\right) \\
& +10^{0.0422 U_{10}+0.288} \sqrt{4 \pi} \exp \left(\frac{r_{80}-2}{2 \log 2}\right) \\
& +10^{0.069 U_{10}-3.5} \sqrt{6 \pi} \exp \left(\frac{r_{80}-12}{2 \log 3}\right) .
\end{aligned}
$$

\section{A6 $\mathbf{5 9 3}$}

Based on a field measurement campaign, Smith et al. (1993) proposed a flux parameterization:

$$
\begin{aligned}
& \frac{\mathrm{d} F}{\mathrm{~d} r_{80}}=10^{0.0676 U_{10}+2.43} \exp \left(-3.1\left(\ln \left[\frac{r_{80}}{2.1}\right]\right)^{2}\right) \\
& +10^{0.959 \sqrt{U_{10}}-1.476} \exp \left(-3.3\left(\ln \left[\frac{r_{80}}{9.2}\right]\right)^{2}\right) .
\end{aligned}
$$

\section{A7 SH98}

SH98 is from Smith and Harrison (1998), and is based on data from one observational campaign:

$$
\begin{aligned}
& \frac{\mathrm{d} F}{\mathrm{~d} r_{80}}=0.2 U_{10}^{3.5} \exp \left(-1.5\left(\ln \left[\frac{r_{80}}{3}\right]\right)^{2}\right) \\
& +6.8 U_{10}^{3} \exp \left(-1\left(\ln \left[\frac{r_{80}}{30}\right]\right)^{2}\right) .
\end{aligned}
$$

\section{A8 LS04}

From a compilation of existing source functions, Lewis and Schwartz (2004) suggested

$\frac{\mathrm{d} F}{\mathrm{~d} r_{80}}=500 U_{10}^{2.5} r_{80}^{-1.65}$.

\section{A9 $\mathbf{A 9 8}$}

A98, created by Andreas (1998), gives this source function:

$$
\begin{aligned}
& \frac{\mathrm{d} F}{\mathrm{~d} r_{80}}=3.5 \cdot 10^{0.0676 U_{10}+2.43} \exp \left(-3.1\left(\ln \left[\frac{r_{80}}{2.1}\right]\right)^{2}\right) \\
& +10^{0.959 \sqrt{U_{10}}-1.476} \exp \left(-3.3\left(\ln \left[\frac{r_{80}}{9.2}\right]\right)^{2}\right) .
\end{aligned}
$$

\section{A10 DL00}

de Leeuw et al. (2000) (DL00) proposed that the surf zone production in winds up to $9 \mathrm{~ms}^{-1}$ can be given as

$\frac{\mathrm{d} F}{\mathrm{~d} D_{\mathrm{p}}}=4 \exp \left(0.23 U_{10}\right) U_{10}^{3.41} r_{80}^{-1.5}$.

It is used in this study as given in de Leeuw et al. (2011). 


\section{A11 A90}

A90 is the source function given in Andreas (1990), as presented in Andreas et al. (1995):

$$
\frac{\mathrm{d} F}{\mathrm{~d} r_{80}}=U_{10}^{2.22} 10^{2.4447-1.6784 L-2.4581 L^{2}+7.7635 L^{3}-3.9667 L^{4}},
$$

where

$$
L=\log \left(r_{80}\right) .
$$

\section{A12 $\mathbf{A 9 2}$}

A92 is from Andreas (1992):

$$
\frac{\mathrm{d} F}{\mathrm{~d} r_{80}}=10^{B_{0}+B_{1}\left(U_{10}\right) L+B_{2},\left(U_{10}^{2}\right) L+B_{1}\left(U_{10}\right) L},
$$

where $L$ is defined as Eq. (A16) and the $B$ 's vary with the wind speed (for values of $B$ see Andreas, 1992).

\section{A13 PP06}

PP06 is from Petelski and Piskozub (2006) (applied as presented as in de Leeuw et al., 2011):

$$
\frac{\mathrm{d} F}{\mathrm{~d} \log D_{\mathrm{p}}}=\frac{70 \exp \left(0.21 U_{10}\right) r_{80}^{3} \exp \left(-0.58 r_{80}\right)}{1-\exp \left(-\frac{0.11 r_{80}^{2}}{U_{10}}\right)}
$$

\section{A14 A07}

A07 is from Andreas (2007), a revised PP06:

$$
\frac{\mathrm{d} F}{\mathrm{~d} r_{80}}=0.4 \cdot \exp \left(\left(0.52 U_{10}+0.64\right) r_{80}\right) \text {. }
$$

\section{A15 N08}

Based on eddy correlation measurements, Norris et al. (2008) suggested

$$
\frac{\mathrm{d} F_{i}}{\mathrm{~d} r_{80, i}}=10^{a_{i}+b_{i} U_{10}}
$$

where

$r_{80, i}=[0.15,0.16,0.19,0.24,0.59,1.25,2.259]$

$a_{i}=[3.90,3.40,2.60,2.60,2.50,2.40,-]$

$b_{i}=[0.24,0.39,0.31,0.28,0.20,0.14,-]$,

where $r_{80, i}$ is the mean bin radius of bin $i$, and $a_{i}$ and $b_{i}$ are the corresponding coefficients. For the largest size, where coefficients are missing, the same values are taken as for the second-largest particles.
Acknowledgements. This work was supported by NordForsk as part of the Nordic Centre of Excellence Cryosphere Atmosphere Interactions in an Arctic Changing Climate (CRAICC). The authors also kindly thank Joseph M. Prospero for sharing his collected data. NOAA PMEL data was made possible, in part, by contributions from NOAA's Climate Program Office. The assistance of P. Eckhardt and A. G. Hjellebrekke with the EBAS database, and EMEP station data suppliers Margaret Ryan (Met. Éiyreann) and W. Aas (NILU) is also acknowledged.

Edited by: H. Skov

\section{References}

Andreas, E. L.: Time constants for the evolution of sea spray droplets, Tellus B, 42, 481-497, 1990.

Andreas, E. L.: Sea spray and the turbulent air-sea heat fluxes, J. Geophys. Res., 97, 11429-11441, 1992.

Andreas, E. L.: A new sea spray generation function for wind speeds up to $32 \mathrm{~m} \mathrm{~s}^{-1}$, J. Phys. Oceanogr., 28, 2175-2184, 1998.

Andreas, E. L.: A review of the sea spray generation function for the open ocean, in: Atmosphere-Ocean Interactions, vol. 1, edited by: Perrie, W., WIT, Southampton, UK, 1-46, 2002.

Andreas, E. L.: Comments on "Vertical coarse aerosol fluxes in the atmospheric surface layer over the North Polar Waters of the Atlantic" by Tomasz Petelski and Jacek Piskozub, J. Geophys. Res., 112, C11010, doi:10.1029/2007JC004184, 2007.

Andreas, E. L., Edson, J. B., Monahan, E. C., Rouault, M. P., and Smith, S. D.: The spray contribution to net evaporation from the sea: a review of recent progress, Bound.-Lay. Meteorol., 72, 352,1995

Antonov, J. I., Locarnini, R. A., Boyer, T. P., Mishonov, A. V., Garcia, H. E., Levitus, S.: World Ocean Atlas 2005 Volume 2: Salinity. NOAA Atlas NESDIS, 62(2), 182 pp., 2006.

Arimoto, R., Duce, R. A., Savoie, D. L., and Prospero, J. M.: Trace elements in the aerosol particles from Bermuda and Barbados: concentrations, sources and relationships to aerosol sulfate, J. Atmos. Chem., 14, 439-457, 1992.

Berner, A., Lürzer, C., Pohl, F., Preining, O., and Wagner, P.: The size distribution of the urban aerosol in Vienna, Science of The Total Environment, 13, 3, 245-261, ISSN 0048-9697, 1979.

Blanchard, D. C.: The electrification of the atmosphere by particles from bubbles in the sea, in: Progression Oceaonography, Pergamon Press, New York, 73-202, 1963.

Blanchard, D. C. and Woodcock, A. H.: Bubble formation and modification in the sea and its meteorological significance, Tellus, 9, 145-158, 1957.

Callaghan, A. H., Deane, G. B., Stokes, M. D., and Ward, B.: Observed variation in the decay time of oceanic whitecap foam, J. Geophys. Res., 117, C09015, doi:10.1029/2012JC008147, 2012.

Clarke, A. D., Owens, S. R., and Zhou, J.: An ultrafine sea salt flux from breaking waves: implications for cloud condensation nuclei in the remote marine atmosphere, J. Geophys. Res., 111, D06202, doi:10.1029/2005JD006565, 2006.

Eckhardt, S., Stohl, A., Beirle, S., Spichtinger, N., James, P., Forster, C., Junker, C., Wagner, T., Platt, U., and Jennings, S. G.: The North Atlantic Oscillation controls air pollution transport to the Arctic, Atmos. Chem. Phys., 3, 1769-1778, doi:10.5194/acp3-1769-2003, 2003. 
Forster, C., Wandinger, U., Wotawa, G., James, P., Mattis, I., Althausen, D., Simmonds, P., O'Doherty, S., Kleefeld, C., Jennings, S. G., Schneider, J., Trickl, T., Kreipl, S., Jäger, H., and Stohl, A.: Transport of boreal forest fire emissions from Canada to Europe, J. Geophys. Res., 106, 22887-22906, 2001.

Frossard, A. A. and Russell, L. M.: Removal of sea salt hydrate water from seawater-derived samples by dehydration, Environ. Sci. Technol., 46, 13326-13333, 2012.

Garrett, T. J., Radke, L. F., and Hobbs, P. V.: Aerosol effects on cloud emissivity and surface longwave heating in the Arctic, Am. Meteorol. Soc., 59, 769-778, 2002.

Garratt, J. R.: Review of Drag Coefficients over Oceans and Continents, Mon. Wea. Rev., 105, 915-929, 1977

Garrett, W. D.: Stabilization of air bubble at the air-sea interface by surface active material, Deep-Sea Res., 14, 661-672, 1967.

Geever, M., O’Dowd, C. D., Ekeren, S. van, Flanagan, R., Nilsson, D. E., de Leeuw, G., and Rannik, Ü.: Submicron sea spray fluxes, Geophys. Res. Lett., 32, 2-5, 2005.

Gemmrich, J. R., Banner, M. L., and Garrett, C.: Spectrally resolved energy dissipation rate and momentum flux of breaking waves, J. Phys. Oceanogr., 38, 1296-1312, 2008.

Gong, S. L. and Bartie, L. A.:Modeling sea-salt aerosols in the atmosphere 1. Model development, J. Geophys. Res., 102, 38053818, 1997.

Gong, S. L.: A parameterization of sea salt aerosol source function for sub and super micron particles, Global Biogeochem. Cy., 17, 1097, doi:10.1029/2003GB002079, 2003.

Holton, J. R.: An Introduction to Dynamic Meteorology, Academic Press, 269-271, 2004.

Hoppel, W. A., Fitzgerald, J. W., Frick, G. M., Larson, R. E., and Mack, E. J.: Atmospheric aerosol size distributions and optical properties found in the marine boundary layer over the Atlantic Ocean, NRL Rep. 9188, Naval Research Laboratory, Washington, DC, 75 pp., 1989.

IPCC: IPPC AR4 The Physical Science Basis, Contribution of Working Group I to the Fourth Assessment Report of the Intergovernmental Panel, edited by: Solomon, S., Qin, D., Manning, M., Chen, Z., Marquis, M., Averyt, K. B., Tignor, M., and Miller, H. L., Cambridge University Press, 2007.

Jaeglé, L., Quinn, P. K., Bates, T. S., Alexander, B., and Lin, J.-T.: Global distribution of sea salt aerosols: new constraints from in situ and remote sensing observations, Atmos. Chem. Phys., 11, 3137-3157, doi:10.5194/acp-11-3137-2011, 2011.

Köhler, H.: Untersuchungen über die Elemente des Nebels und der Wolken, Meddelanden Från Statens MeteorologiskHydrografiska Anstalt, 2, 1-73, 1925.

Leeuw, G. De, Neele, F. P., Hill, M., Smith, M. H., and Vignati, E.: Sea spray aerosol production by waves breaking in the surf zone, J. Geophys. Res., 105, 29397-29409, 2000.

Leeuw, G. De, Andreas, E. L., Anguelova, M. D., Fairall, C. W., Lewis, E. R., Dowd, C. O., Schulz, M., and Schwartz, S. E.: Production flux of sea spray aerosol, Rev. Geophys., 49, 1-39, 2011.

Lewis, E. R. and Schwartz, S. E.: Sea Salt Aerosol Production: Mechanisms, Methods, Measurements and Models - a Critical Review, Geophys. Monogr. Ser., vol. 152, AGU, Washington, D.C., 413 pp., 2004.

Mårtensson, E. M., Nilsson, E. D., de Leeuw, G., Cohen, L. H., and Hansson, H. C.: Laboratory simulations and parameterization of the primary marine aerosol production, J. Geophys. Res., 108, $1-12,2003$.

Massel, S. R: Ocean waves breaking and marine aerosol fluxes, Vol. 38. Springer, 11-27, 2007.

Monahan, E. C. and O'Muircheartaigh, I.: Optimal power-law description of oceanic whitecap coverage dependence on wind speed, J. Phys. Oceanogr., 10, 2094-2099, 1980.

Monahan, E. C., Spiel, D. E., and Davidson, K. L.: A model of marine aerosol generation via whitecaps and wave disruption, in: Oceanic Whitecaps and Their Role in Air-Sea Exchange Processes, edited by: Monahan, E. C. and MacNiocaill, G., D. Reidel, Dordrecht, the Netherlands, 167-174, 1986.

Monin, A. S. and Obukhov, A.: Basic laws of turbulent mixing in the surface layer of the atmosphere, Contrib. Geophys. Inst. Acad. Sci. USSR, 151, 163-187, 1954.

Norris, S. J., Brooks, I. M., de Leeuw, G., Smith, M. H., Moerman, M., and Lingard, J. J. N.: Eddy covariance measurements of sea spray particles over the Atlantic Ocean, Atmos. Chem. Phys., 8, 555-563, doi:10.5194/acp-8-555-2008, 2008.

O'Dowd, C. D. and de Leeuw, G.: Marine aerosol production: a review of the current knowledge, Philos. T. Roy. Soc. A, 365, 1753-1774, 2007.

O'Dowd, C. D., Facchini, M. C., Cavalli, F., Ceburnis, D., Mircea, M., Decesari, S., Fuzzi, S., Yoon, Y. J., and Putaud, J.: Biogenically driven organic contribution to marine aerosol, Nature, 431, 676-679, 2004.

Petelski, T. and Piskozub, J.: Vertical coarse aerosol fluxes in the atmospheric surface layer over the North Polar Waters of the Atlantic, J. Geophys. Res., 111, C06039, doi:10.1029/2005JC003295, 2006.

Prandtl, L.: Meteorologische Anwendung der Strömungslehre, Beitr. Physik der freien Atmosphäre, Bjerknes Festschrift, 188202, 1932

Prospero, J. M., Savoie, D. L., and Arimoto, R.: Long-term record of nss-sulfate and nitrate in aerosols on Midway Island, 1981-2000: evidence of increased (now decreasing?) anthropogenic emissions from Asia, J. Geophys. Res., 108, 4019, doi:10.1029/2001JD001524, 2003.

Prospero, J. M., Blades, E., Mathison, G., and Naidu, R.: Interhemispheric transport of viable fungi and bacteria from Africa to the Caribbean with soil dust, Aerobiologia, 21, 1-19, 2005.

Reid, J. S., Jonsson, H. H., Smith, M. H., and Smirnov, A.: Evolution of the vertical profile and flux of large sea-salt particles in a coastal zone, J. Geophys. Res., 106, 39-53, 2001.

Saltzman, E. S., Savoie, D. L., Prospero, J. M., and Zika, R. G.: Atmospheric methanesulfonic acid and non-sea-salt sulfate at Fanning and American Samoa, Geophys. Res. Lett., 12, 437-440, 1985.

Seibert, P. and Frank, A.: Source-receptor matrix calculation with a Lagrangian particle dispersion model in backward mode, Atmos. Chem. Phys., 4, 51-63, doi:10.5194/acp-4-51-2004, 2004.

Sellegri, K., O’Dowd, C. D., Yoon, Y. J., Jennings, S. G., and de Leeuw, G.: Surfactants and submicron sea spray generation, J. Geophys. Res., 111, 1-12, 2006.

Smith, M. H. and Harrison, N. M.: The sea spray generation function, J. Aerosol Sci., 29, 189-190, doi:10.1016/S00218502(98)00280-8, 1998. 
Smith, M. H., Park, P. M., and Consterdine, I. E.: Marine aerosol concentrations and estimated fluxes over the sea, Q. J. Roy. Meteor. Soc., 119, 809-824, 1993.

Sofiev, M., Soares, J., Prank, M., de Leeuw, G., and Kukkonen, J.: A regional-to-global model of emission and transport of sea salt particles in the atmosphere, J. Geophys. Res., 116, D21302, doi:10.1029/2010JD014713, 2011.

Stohl, A.: Characteristics of atmospheric transport into the Arctic troposphere, J. Geophys. Res., 111, 1-17, 2006.

Stohl, A. and Thomson, D. J.: A density correction for lagrangian particle dispersion models, Bound.-Lay. Meteorol., 90, 155-167, 1999.

Stohl, A., Forster, C., Eckhardt, S., Spichtinger, N., Huntrieser, H., Heland, J., Schlager, H., Wilhelm, S., Arnold, F., and Cooper, O.: A backward modeling study of intercontinental pollution transport using aircraft measurements, J. Geophys. Res., 108, 4370, doi:10.1029/2002JD002862, 2003.

Stohl, A., Forster, C., Frank, A., Seibert, P., and Wotawa, G.: Technical note: The Lagrangian particle dispersion model FLEXPART version 6.2, Atmos. Chem. Phys., 5, 2461-2474, doi:10.5194/acp-5-2461-2005, 2005.

Stohl, A., Seibert, P., Arduini, J., Eckhardt, S., Fraser, P., Greally, B. R., Lunder, C., Maione, M., Mühle, J., O’Doherty, S., Prinn, R. G., Reimann, S., Saito, T., Schmidbauer, N., Simmonds, P. G., Vollmer, M. K., Weiss, R. F., and Yokouchi, Y.: An analytical inversion method for determining regional and global emissions of greenhouse gases: sensitivity studies and application to halocarbons, Atmos. Chem. Phys., 9, 1597-1620, doi:10.5194/acp-9-1597-2009, 2009.

Stohl, A., Prata, A. J., Eckhardt, S., Clarisse, L., Durant, A., Henne, S., Kristiansen, N. I., Minikin, A., Schumann, U., Seibert, P., Stebel, K., Thomas, H. E., Thorsteinsson, T., Tørseth, K., and Weinzierl, B.: Determination of time- and height-resolved volcanic ash emissions and their use for quantitative ash dispersion modeling: the 2010 Eyjafjallajökull eruption, Atmos. Chem. Phys., 11, 4333-4351, doi:10.5194/acp-11-4333-2011, 2011.

Textor, C., Schulz, M., Guibert, S., Kinne, S., Balkanski, Y., Bauer, S., Berntsen, T., Berglen, T., Boucher, O., Chin, M., Dentener, F., Diehl, T., Easter, R., Feichter, H., Fillmore, D., Ghan, S., Ginoux, P., Gong, S., Grini, A., Hendricks, J., Horowitz, L., Huang, P., Isaksen, I., Iversen, I., Kloster, S., Koch, D., Kirkevåg, A., Kristjansson, J. E., Krol, M., Lauer, A., Lamarque, J. F., Liu, X., Montanaro, V., Myhre, G., Penner, J., Pitari, G., Reddy, S., Seland, Ø., Stier, P., Takemura, T., and Tie, X.,: Analysis and quantification of the diversities of aerosol life cycles within AeroCom, Atmos. Chem. Phys., 6, 1777-1813, doi:10.5194/acp-61777-2006, 2006.
Thorpe, S. A., Bowyer, P., and Woolf, D. K.: Some factors affecting the size distributions of oceanic bubbles, J. Phys. Oceanogr., 22, 382-389, 1992.

Tsyro, S., Aas, W., Soares, J., Sofiev, M., Berge, H., and Spindler, G.: Modelling of sea salt concentrations over Europe: key uncertainties and comparison with observations, Atmos. Chem. Phys., 11, 10367-10388, doi:10.5194/acp-1110367-2011, 2011.

Twomey, S.: The influence of pollution on the shortwave albedo of clouds, J. Atmos. Sci., 34, 1149-1152, 1977.

Uppala, S. M., Kållberg, P. W., Simmons, A. J., Andrae, U., Da Costa Bechtold, V., Fiorino, M., Gibson, J. K., Haseler, J., Hernandez, A., Kelly, G. A., Li, X., Onogi, K., Saarinen, S., Sokka, N., Allan, R. P., Andersson, E., Arpe, K., Balmaseda, M. A., Beljaars, A. C. M., van de Berg, L., Bidlot, J., Bormann, N., Caires, S., Chevallier, F., Dethof, A., Dragosavac, M., Fisher, M., Fuentes, M., Hagemann, S., Hólm, E., Hoskins, B. J., Isaksen, L., Janssen, P. A. E. M., Jenne, R., McNally, A. P., Mahfouf, J.-F., Morcrette, J.-J., Rayner, N. A., Saunders, R. W., Simon, P., Sterl, A., Trenberth, K. E., Untch, A., Vasiljevic, D., Viterbo, P., and Woollen, J.: The ERA-40 re-analysis, Q. J. Roy. Meteor. Soc., 131, 2961-3012, 2005

Vignati, E., de Leeuw, G., and Berkowicz, R.: Modeling coastal aerosol transport and effects of surf-produced aerosols on processes in the marine atmospheric boundary layer, J. Geophys. Res.-Atmos., 106, 20225-20238, 2001.

Zábori, J., Krejci, R., Ekman, A. M. L., Mårtensson, E. M., Ström, J., de Leeuw, G., and Nilsson, E. D.: Wintertime Arctic Ocean sea water properties and primary marine aerosol concentrations, Atmos. Chem. Phys., 12, 10405-10421, doi:10.5194/acp-12-10405-2012, 2012a.

Zábori, J., Matisäns, M., Krejci, R., Nilsson, E. D., and Ström, J.: Artificial primary marine aerosol production: a laboratory study with varying water temperature, salinity, and succinic acid concentration, Atmos. Chem. Phys., 12, 10709-10724, doi:10.5194/acp-12-10709-2012, 2012b. 